\title{
A three-pillar approach to assessing climate impacts on low flows
}

\author{
Gregor Laaha ${ }^{1}$, Juraj Parajka² ${ }^{2}$ Alberto Viglione ${ }^{2}$, Daniel Koffler ${ }^{1}$, Klaus Haslinger ${ }^{3}$, Wolfgang Schöner ${ }^{4}$, \\ Judith Zehetgruber ${ }^{1}$, and Günter Blöschl ${ }^{2}$ \\ ${ }^{1}$ Institute of Applied Statistics and Computing, University of Natural Resources and Life Sciences (BOKU), Vienna, Austria \\ ${ }^{2}$ Institute for Hydraulic and Water Resources Engineering, Vienna University of Technology, Vienna, Austria \\ ${ }^{3}$ Climate Research Department, Central Institute for Meteorology and Geodynamics, Vienna, Austria \\ ${ }^{4}$ Department of Geography and Regional Science, University of Graz, Graz, Austria
}

Correspondence to: G. Laaha (gregor.laaha@boku.ac.at)

Received: 7 November 2015 - Published in Hydrol. Earth Syst. Sci. Discuss.: 15 December 2015

Revised: 22 June 2016 - Accepted: 26 August 2016 - Published: 27 September 2016

\begin{abstract}
The objective of this paper is to present a framework for assessing climate impacts on future low flows that combines different sources of information, termed pillars. To illustrate the framework three pillars are chosen: (a) extrapolation of observed low-flow trends into the future, (b) rainfall-runoff projections based on climate scenarios and (c) extrapolation of changing stochastic rainfall characteristics into the future combined with rainfall-runoff modelling. Alternative pillars could be included in the overall framework. The three pillars are combined by expert judgement based on a synoptic view of data, model outputs and process reasoning. The consistency/inconsistency between the pillars is considered an indicator of the certainty/uncertainty of the projections. The viability of the framework is illustrated for four example catchments from Austria that represent typical climate conditions in central Europe. In the Alpine region where winter low flows dominate, trend projections and climate scenarios yield consistently increasing low flows, although of different magnitudes. In the region north of the Alps, consistently small changes are projected by all methods. In the regions in the south and south-east, more pronounced and mostly decreasing trends are projected but there is disagreement in the magnitudes of the projected changes. The process reasons for the consistencies/inconsistencies are discussed. For an Alpine region such as Austria the key to understanding low flows is whether they are controlled by freezing and snowmelt processes, or by the summer moisture deficit associated with evaporation. It is argued that the three-pillar approach offers a systematic framework of combining different sources of information aimed at more robust projections than that obtained from each pillar alone.
\end{abstract}

\section{Introduction}

Streamflow regimes are changing around the world due to multiple factors, and low flows are often particularly affected. Direct human impacts, such as abstractions, and climate impacts are difficult to isolate (Blöschl and Montanari, 2010), yet understanding the causes of changes is essential for many water management tasks. Research into assessing low-flow and drought changes falls into two groups (Sivapalan et al., 2003).

The first group infers catchment functioning from an interpretation of the observed streamflow response at the catchment scale. It includes statistical trend analyses of observed low-flow characteristics, such as the annual minima, supported by analyses and interpretations of the process causes (e.g. Giuntoli et al., 2013, in France, Hannaford and Buys, 2012, in the UK, Wilson et al., 2010, in the Nordic countries, Lorenzo-Lacruz et al., 2012, on the Iberian Peninsula, and Lins and Slack, 1999, and Douglas et al., 2000, in the USA). Most trend analyses are performed locally on a station-bystation basis and are therefore not fully conclusive at the larger scale of climate processes. Regional trend analyses are based on field significance statistics or block-bootstrapping procedures (e.g. Renard et al., 2008; Wilson et al., 2010) or, alternatively, a regional interpretation of trend patterns (e.g. Stahl et al., 2010). Most studies perform trend interpretations in a heuristic way without cross-checking against alternative sources of information.

The second group involves a model cascade, where general circulation model (GCM) outputs are fed into regional climate models (RCMs), the outputs of which (usually pre- 
cipitation and air temperature) are fed into hydrological models to project future streamflows. Low-flow examples include De Wit et al. (2007) for the Meuse, Hurkmans et al. (2010) for the Rhine and Majone et al. (2012) for the Gállego river in Spain. National studies include Wong et al. (2011) in Norway, Prudhomme et al. (2012) in the UK, Chauveau et al. (2013) in France and Blöschl et al. (2011) in Austria. The hydrological models used in these studies are often not specifically parameterised for low flows, which results in considerable uncertainties.

The two approaches have relative strengths and weaknesses (see Hall et al., 2014, for the flood case). The first approach makes fewer assumptions and is more directly based on observations, but any extrapolation into the future is more speculative. Recent changes in air temperature have been quite consistent over time in many parts of the world. In the European Alps, for example, the increase in air temperature since 1980 has been about $0.5^{\circ} \mathrm{C} \mathrm{decade}^{-1}$ with little variation between the decades (Böhm et al., 2001; Auer et al., 2007), and the expected trends are similar. If one assumes that air temperature is the main driver of low-flow changes, persistence of low-flow changes into the near future is therefore a reasonable assumption. Of course, such an extrapolation hinges on the realism of the assumptions and is likely only applicable to a limited time horizon. The second approach on the other hand is more process based so has more potential for projections into the future, but the spatial resolution of the atmospheric models is rather coarse (e.g. $10 \mathrm{~km}$ for dynamically downscaled reclip:century simulations), so small-scale climate features, such as cloud formation and rainfall generation, cannot be resolved. As a consequence, air temperature projections tend to be more robust than precipitation projections, in particular in Alpine landscapes (Field and Intergovernmental Panel on Climate Change, 2012; Haslinger et al., 2013). There is value therefore in confronting such projections with results from other approaches.

\section{Three-pillar approach}

In this paper we propose a framework that combines complementary pieces of information on low flows in order to enhance the reliability of the projections. The overall philosophy has been inspired by the concept of multi-model climate projections, where the projections from a group of models together are considered to be more robust than the individual projections, and the difference between the individual models represents an indicator of the uncertainty associated with the projections. Knutti et al. (2010), for example, states

Ensemble: A group of comparable model simulations. The ensemble can be used to gain a more accurate estimate of a model property through the provision of a larger sample size, e.g., of a climatological mean of the frequency of some rare event.
Variation of the results across the ensemble members gives an estimate of uncertainty.

While the climate models Knutti et al. (2010) are referring to are similar in their basic design and only differ in specific process representations, the notion of inferring predictive reliability from model consistency builds on the broader principle of consilience, which suggests that, if multiple sources of independent evidence are in agreement, the conclusion can be very strong even if the individual sources do not provide strong evidence on their own (Wilson, 1998). Combining different sources of information has a long tradition in various fields of hydrology such as flood estimation (Stedinger and Tasker, 1985; Gutknecht et al., 2006; Merz and Blöschl, 2008), low-flow estimation, (Laaha and Blöschl, 2007) and, more generally, uncertainty estimation in ungauged basins (Gupta et al., 2013).

The combination can be based on formal methods such as Bayesian statistics (Viglione et al., 2013) or on a heuristic process reasoning based on expert judgement (Merz and Blöschl, 2008). The latter is able to account for a broader class of information sources but it is more subjective. In this paper, we chose a heuristic approach because of its flexibility but, as demonstrated by Viglione et al. (2013), this could be formalised.

We illustrate the framework by choosing three pillars or sources of information to assist in projecting low flows into the future. The first pillar consists of extrapolating observed low-flow trends into the future. The second pillar consists of rainfall-runoff projections driven by GCM-based climate scenarios. The third pillar extrapolates observed trends in stochastic rainfall and temperature characteristics into the future, combined with rainfall-runoff modelling. Alternative or additional pillars could be used, e.g. the "trading space for time" approach (Perdigão and Blöschl, 2014) where spatial gradients are transposed into temporal changes.

The data and assumptions about the three pillars differ, so one would also expect the error structures to be different which will have a number of benefits for the projections. Comparisons of observed and simulated low-flow time series at the decadal timescale provide insight into the performance of the runoff models as well as the climate hindcasts, which gives an indication of their performance for the future. The analysis and projection of the stochastic climate and low-flow behaviour shed light on their co-behaviour, the sensitivity of low flows to changing climate variables and the role of noise over decadal timescales. Finally, the consistency of the projections by the different methods sheds light on the robustness of the overall projections.

We demonstrate the viability of the approach for four example regions in Austria and discuss the findings in the context of hydrological climate impact studies. 


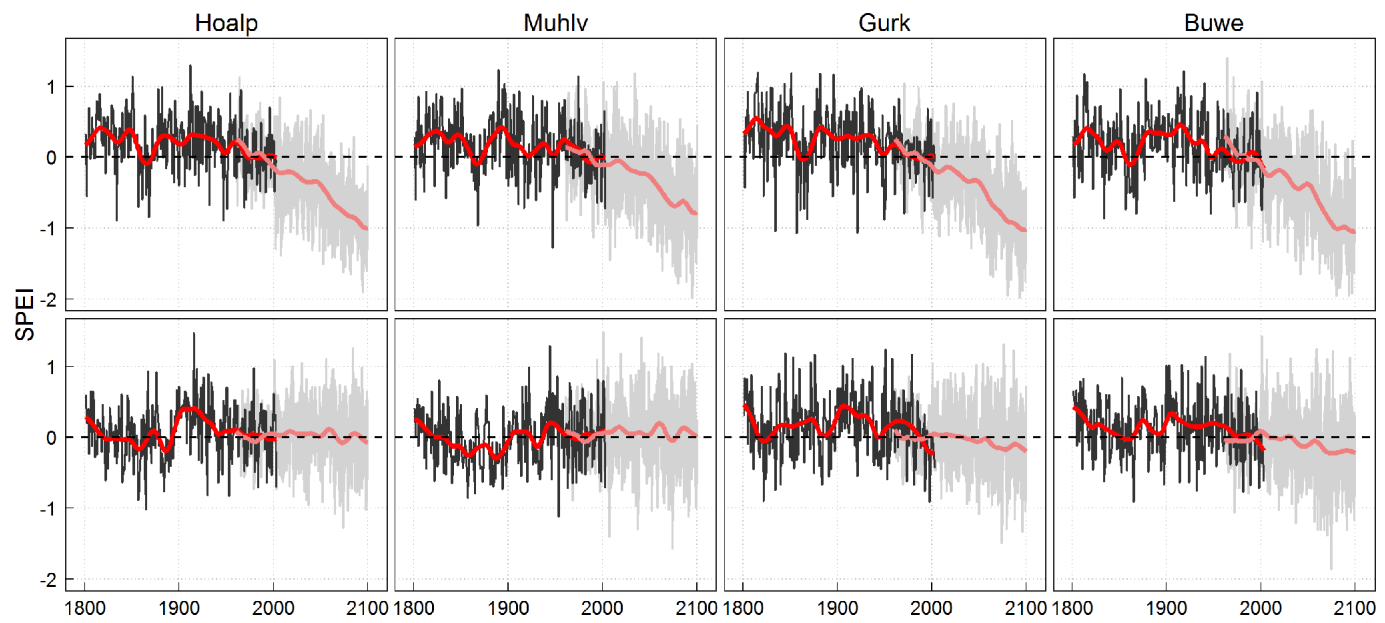

Figure 1. Standardized Precipitation Evaporation Index (SPEI) in summer (top) and winter (bottom) (3-month averages of monthly values) for the four example catchments. Observed (HISTALP, Auer et al., 2007, black) and projected (reclip:century ensemble spread, grey). Red and light red lines represent the Gaussian low-pass filtered values of the observed and projected SPEI, respectively.

\section{Case study regions and data}

The four example regions are representative of the main climatological units in Austria. Although Austria is quite diverse, each of these regions is rather homogeneous in terms of climate and hydrological regime. Within each region, a typical catchment was selected guided by previous low-flow and drought studies (Haslinger et al., 2014; Van Loon and Laaha, 2015).

The Hoalp region (for Hochalpen) is located in the Alps and exhibits a clear winter low-flow regime where freeze and snow processes are important, so long-term trends are expected to be related to changing air temperatures. The region is represented by the Matreier Tauernhaus catchment at the Tauernbach $\left(60 \mathrm{~km}^{2}\right.$ area, $1502 \mathrm{~m}$ a.s.l. altitude). The Muhlv region (for Mühlviertel) is located north of the Alps and exhibits a dominant summer low-flow regime as a result of summer precipitation and evaporation, so precipitation and air temperature will be important low-flow controls. The region is represented by the Hartmannsdorf catchment at the Steinerne Mühl $\left(138 \mathrm{~km}^{2}\right.$ area, $500 \mathrm{~m}$ altitude). The Gurk region (for Gurktal) is located south of the Alps and also exhibits a dominant summer low-flow regime. Precipitation enters the area from the north-west through Atlantic cyclones, although screened to some extent by the Alps, as well as from the south through Mediterranean cyclones. Precipitation and air temperature are important for low flows. The region is represented by the Zollfeld catchment at the Glan $\left(432 \mathrm{~km}^{2}\right.$ area, $453 \mathrm{~m}$ altitude). The Buwe region (for Bucklige Welt) is located in the south-east of Austria in the lee of the Alps, at the transition to a Pannonic climate. The precipitation is lowest in this region. Low flows mainly occur in summer with precipitation and air temperature as important controls. The region is represented by the Altschlaining catchment at the Tauchenbach $\left(89 \mathrm{~km}^{2}\right.$ area, $316 \mathrm{~m}$ altitude). Streamflow records in the four catchments over the period 1976-2008 were used for all three pillars.

Climate records were used for the second and third pillars. Gridded data sets of daily precipitation, air temperature and potential evaporation over the period 1976-2008 were used for calibrating the hydrological model. These data are based on measured daily precipitation at 1091 stations and daily air temperature at 212 stations. Potential evaporation was estimated by a modified Blaney-Criddle method based on daily air temperature and potential sunshine duration (Parajka et al., 2007). For each catchment, precipitation and temperature records at one representative station over the period 19482010 were analysed as a basis of the stochastic simulations (third pillar).

\section{Methods used for the pillars}

\subsection{Extrapolation of observed low-flow trends}

The streamflow records of the four stream gauges were analysed to estimate $Q_{95}$ low-flow quantiles (i.e. the flow that is exceeded $95 \%$ of the time) for each year. The serial correlations of these annual low-flow series were mostly insignificant, so they were not prewhitened (Yue et al., 2002). Trends were tested for significance by a standard Mann-Kendall test. The trends were estimated as the medians of all slopes between pairs of sample points (Sen's slope, Sen, 1968) with regression parameters $\hat{a}$ and $\hat{b}$ :

$\hat{Q}_{95}\left(t_{0}\right)=\hat{a}+\hat{b} t_{0}$.

The uncertainty of the trends was assessed by a nonparametric bootstrapping approach, which provides accurate confidence bounds in the case of non-Gaussian regression 
residuals (Efron and Tibshirani, 1993). The approach simulates the uncertainty distribution of trend estimates at time $t_{0}$ by resampling 5000 replications from the annual $Q_{95}$ series and calculating the regression parameters $\hat{a}$ and $\hat{b}$ for each of them. Equation (1) applied to these parameter distributions yields the uncertainty distribution of trend estimates at time $t_{0}$, and its 0.025 and 0.975 empirical quantiles constitute the bounds of a two-sided $95 \%$ confidence interval.

For the purpose of this paper, we assumed that the trends are linear and persistent, and so extrapolated them into the future. This is of course a strong assumption less likely to be valid with increasing time horizon.

\subsection{Climate projections and runoff modelling}

Four runs from the regional climate model COSMO in CLimate Mode (COSMO-CLM) provided by the reclip:century1 project (Loibl et al., 2011) were used. The runs had been obtained from ECHAM5 and HADCM3 GCMs forced by three IPCC emission scenarios (A1B, B1 and A2). These scenarios were selected for consistency with other ongoing studies in Austria (e.g. Parajka et al., 2016). In order to check their realism with respect to droughts and low flows, the Standardized Precipitation Evaporation Index (SPEI; Vicente-Serrano et al., 2010) was evaluated, which is the Gaussian-transformed standardised monthly difference of precipitation and evaporation. Values below zero indicate deficits in the climatic water balance, and values below -1 indicate drought conditions. The SPEI has been adopted here for its simplicity and because it can be calculated from the HISTALP data (Auer et al., 2007) back to the year 1800. Haslinger et al. (2014) demonstrated that the SPEI is correlated well with summer low flows in the study region. In the winter (Fig. 1, bottom panels), the simulations (light red lines) for Hoalp and Muhlv seem to be more consistent with decadal observed fluctuations from the HISTALP data set (red lines) than for Gurk and Buwe. Note that the comparison should focus on the long-term (decadal) dynamics rather than individual years due to the nature of the climate simulations. Overall, SPEI remains rather stable, which is due to little change in winter precipitation. In the summer (Fig. 1, top panels), the simulations are somewhat less consistent with the observations than for the winter, in particular for Buwe where the simulations show a decreasing trend in the overlapping period (19612003), while the observations show little change. Overall, the summer SPEI projections show a decreasing trend indicating a dryer future and the trend tends to steepen beyond 2050 . This is mainly due to the precipitation characteristics of the ECHAM5 simulations used and not reflected in the other models or ECHAM5 runs. The extremely negative trends in the summer SPEI should therefore be treated with caution.

Runoff is simulated by the delta-change approach (e.g. Hay et al., 2000; Diaz-Nieto and Wilby, 2005). A conceptual rainfall-runoff model (TUWmodel) is used here, which simulates the daily water balance components from pre- cipitation, air temperature and potential evaporation inputs (Viglione and Parajka, 2014; Parajka et al., 2007; Ceola et al., 2015). The routing component of the model, which is most relevant for low flows, consists of a number of reservoirs with different storage coefficients. Specifically, excess rainfall enters the upper zone reservoir and leaves this reservoir through three paths: outflow from the reservoir based on a fast storage coefficient; percolation to the lower zone with a constant percolation rate; and, if a threshold of the storage state is exceeded, through an additional outlet based on a very fast storage coefficient. Water leaves the lower zone based on a slow storage coefficient. The model parameters (including the reservoir parameters representing groundwater storage) were calibrated against observed streamflow by the SCE-UA procedure (Parajka et al., 2007; Duan et al., 1992). The objective function $\left(Z_{Q}\right)$ was chosen on the basis of prior analyses in the study region (Parajka and Blöschl, 2008) as

$$
Z_{Q}=w_{Q} \cdot M_{E}+\left(1-w_{Q}\right) \cdot M_{E}^{\log },
$$

where $w_{Q}$ and $\left(1-w_{Q}\right)$ are the weights on high and low flows, respectively, and $M_{E}$ and $M_{E}^{\log }$ are estimated as

$$
\begin{aligned}
M_{E} & =1-\frac{\sum_{i=1}^{n}\left(Q_{\mathrm{obs}, i}-Q_{\mathrm{sim}, i}\right)^{2}}{\sum_{i=1}^{n}\left(Q_{\mathrm{obs}, i}-\overline{Q_{\mathrm{obs}}}\right)^{2}}, \\
M_{E}^{\log } & =1-\frac{\sum_{i=1}^{n}\left(\log \left(Q_{\mathrm{obs}, i}\right)-\log \left(Q_{\mathrm{sim}, i}\right)\right)^{2}}{\sum_{i=1}^{n}\left(\log \left(Q_{\mathrm{obs}, i}\right)-\overline{\log \left(Q_{\mathrm{obs}}\right)}\right)^{2}} .
\end{aligned}
$$

$Q_{\mathrm{obs}, i}$ is the observed discharge on day $i, \overline{Q_{\mathrm{obs}}}$ is its average over the calibration (or verification) period of $n$ days, and $Q_{\text {sim }, i}$ is the simulated discharge.

In order to assess the uncertainty of low-flow projections from a hydrological modelling perspective, different calibration variants were evaluated by varying the weights of Eq. (2), following the methodology of Parajka et al. (2016). In order to assess the impact of time stability of the model parameters, the model was calibrated separately for three different periods (1976-1986, 1987-1997, 1998-2008), following the methodology of Merz et al. (2011).

Air temperatures and precipitation of the four regional climate model runs were then evaluated for a reference period (1976-2008) and compared with two future periods (20212050 and 2051-2080) for each month separately. The differences (delta) were added to the observed daily air temperatures and precipitation values for the four catchments from which future streamflow was simulated using the rainfallrunoff model.

\subsection{Extrapolation of stochastic rainfall characteristics and runoff modelling}

A stochastic model is used to investigate what would happen if the trend of observed precipitation and air temperature characteristics in the period 1948-2010 would persist into the 


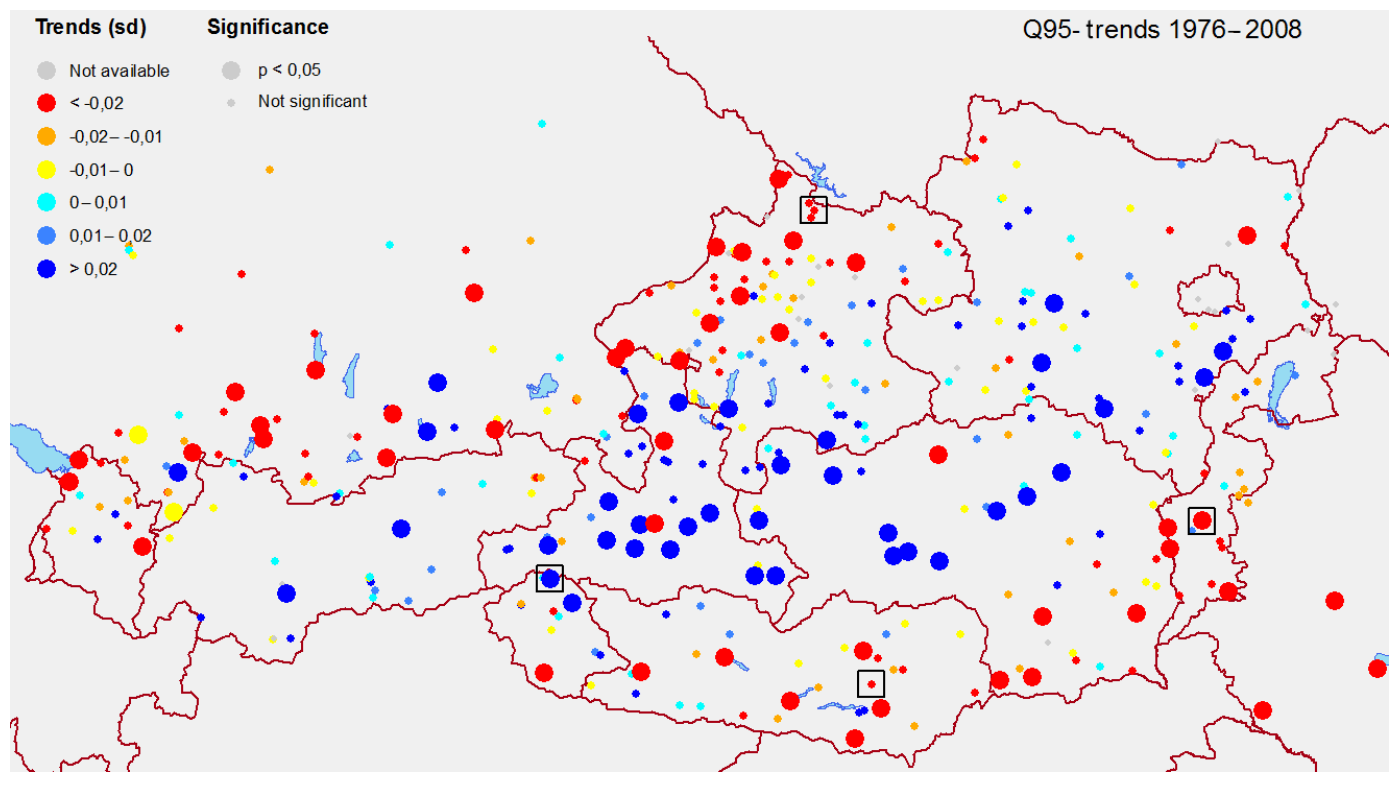

Figure 2. Observed trends of annual $Q_{95}$ low flows in Austria in the period 1976-2008. Colours correspond to the sign and the magnitude of the trends (blue is increasing, red is decreasing). Size indicates significance of trends. Units of the trends are standard deviations per year. Squares indicate example catchments.

future. The results of the stochastic model are used to drive a lumped version of the TUWmodel, which is similar to the one used in the delta-change approach.

The precipitation model is the point model of Sivapalan et al. (2005), which simulates discrete rainfall events whose storm durations, interstorm periods and average event rainfall intensities are all random, governed by specified distributions whose parameters vary seasonally. The model was run on a daily time step without considering within-storm rainfall patterns as the interest was in low flows. A stormseparation algorithm was applied to the precipitation data of the four stations, based on a minimum duration of dry periods, in order to isolate precipitation events. From the event time series the temporal trends of three model parameters (mean annual storm duration, mean annual inter-storm period and mean annual storm intensity) were estimated by the Theil-Sen algorithm, to serve as the trend components of the precipitation model. The trends in these precipitation model components were subsequently extrapolated into the future. Similar to the low-flow extrapolation, this is a strong assumption less likely to be valid with an increasing time horizon. The remaining rainfall model parameters were calibrated to the precipitation data as described in Viglione et al. (2012) and were kept constant for the entire simulation period. The stochastic rainfall model was finally used to simulate an ensemble of 100 possible time series of precipitation affected by trends in the three model parameters for the period 19482080.

For air temperature, instead, 100 possible time series were obtained by randomising the observations in the following way. The time series of daily temperatures were detrended
Table 1. Trend estimates of observed $Q_{95}$ low flows in the period 1976-2008 (Mann-Kendall test). Relative trends refer to the trend over the observation period relative to its mean.

\begin{tabular}{lrrrr}
\hline & Hoalp & Muhlv & Gurk & Buwe \\
\hline $\begin{array}{l}\text { Trend } \\
\left(\mathrm{m}^{3} \mathrm{~s}^{-1} \text { per 100 years }\right)\end{array}$ & $+0.24^{* *}$ & -0.28 & -1.45 & $-0.34^{*}$ \\
$\begin{array}{l}\text { Relative trend } \\
(\% \text { per year })\end{array}$ & $+1.21^{* *}$ & -0.38 & -0.78 & $-1.88^{*}$ \\
$p$ value & 0.009 & 0.377 & 0.053 & 0.045 \\
\hline
\end{tabular}

Significance codes: ${ }^{* *} p<0.01 ;^{*} p<0.05$.

according to the observed trend of mean annual temperatures, the years were randomly mixed (with repetition) and the trend was added to the reshuffled series. The trend in the temperatures was reflected by an analogous trend in potential evaporation.

\section{Results}

\subsection{Extrapolation of observed low-flow trends}

Table 1 summarises the results of the trend analyses of $Q_{95}$ low flows. The Hoalp catchment exhibits a significantly increasing trend indicating that the catchment has become wetter over the observation period while the Buwe catchment indicates a significantly decreasing trend. Muhlv and Gurk show decreasing trends that are, however, not significant at the 0.05 level. 
While our focus is on the four example catchments, it is important to put the local analyses in a regional context to avoid the detection of local effects on the flow regime, such as anthropogenic impacts. Equally important, the regional context assists in a more meaningful interpretation of regional climate scenarios that are valid for footprints of a few hundreds of square kilometres or more. Figure 2 shows the trends of the four example catchments together with trends of 408 stream gauges in Austria and neighbouring regions. The trend patterns are in line with the main hydro-climatic units represented by the four catchments. Significantly increasing trends (large blue points) such as in the Hoalp catchment are generally found in the Alpine region. Decreasing trends (large red points) occur north of the Alps and, more frequently, in the south-eastern part of Austria. Additional regional analyses (not shown here), including field significance testing, confirm the finding that the decreasing trends in the south-east are more significant than in the north. The Buwe region appears to be particularly affected by climate change as low flows show a strong decrease at the end of the observation period.

Table 2 presents the trend extrapolations together with their confidence bounds. Extrapolating observed trends to 2021-2050 would give a $39 \%$ increase in $Q_{95}$ for Hoalp, but the uncertainty is large, as indicated by a range of the confidence interval from -7 to $71 \%$. Trend extrapolations for the other catchments result in decreases that are the smallest in Muhlv $(-8 \%)$, moderate in Gurk $(-36 \%)$ and the largest in Buwe $(-90 \%)$. The uncertainty range is large, e.g. -41 to $+34 \%$ for Muhlv, which is almost 10 times the mean change. Clearly, trend extrapolations involve a lot of uncertainty, and this uncertainty increases as one moves to the more distant time horizon of 2051-2080 (Table 2), including negative discharges for Buwe and Gurk indicating intermittent behaviour. Obviously, one would have very low confidence in the absolute figures of such trend scenarios for the more distant future.

\subsection{Climate projections and runoff modelling}

Table 3 summarises the runoff model efficiencies $Z_{Q}$ for different weights in the objective function. $w_{Q}=0$ emphasises low flows, while $w_{Q}=1$ emphasises high flows in the calibration. With the exception of Gurk, there is a clear trend of increasing (calibration) model performance from high flows to low flows. The model performance between the calibration decades varies little. Overall, Hoalp gives the largest efficiency, which is a reflection of the strong seasonality associated with snow storage and melt while Buwe gives the lowest efficiency due to the flashy nature of runoff that is difficult to model on a daily time step (Fig. 3). The flashy runoff response of Buwe is related to shallow soils, efficient drainage and frequent convective storms (see Gaál et al., 2012). Additionally, there are only two climate stations in the Buwe catchment, so local precipitation events may not always be captured well. The event variability is large between and within the years (Fig. 3). Both low flows and floods mainly occur in summer. As compared to other catchments in Austria (Parajka et al., 2016), the Hoalp and Buwe catchments represent typical conditions of high and low model performances, respectively.

Figure 4 (left panel) shows the simulated annual $Q_{95}$ low flows for the reference period 1976-2008, based on calibrations for two subperiods (yellow and blue), in each case indicating the variability of $Q_{95}$ due to 11 calibration variants with different weights $w_{Q}$ in the objective function (Table 3). The right panels show the simulations for two sets of weights (light orange and red), in each case indicating the variability of $Q_{95}$ due to model parameters obtained from different decades. Although the model has not specifically been calibrated to $Q_{95}$, it simulates $Q_{95}$ rather well. The differences between the two weighting variants (Fig. 4 right) are small in absolute terms. The effect of temporal instability of the model parameters is clearly visible in Buwe and Gurk (Fig. 4 left), as the model calibrated to the 1976-1986 period tends to overestimate $Q_{95}$ in the period 1998-2008. The decade 1976-1986 represents a colder period with less evaporation and relatively higher runoff generation rates, which is reflected by lower values of the soil moisture storage parameter (FC) and lower values of the parameter controlling runoff generation (BETA). The model therefore overestimates runoff when applied to the drier and warmer period 1998-2008. Even though Table 3 indicates that Buwe has the lowest model performance, this is not reflected in the $Q_{95}$ low-flow simulations in Fig. 4. This is because the model does not simulate the fast runoff fluctuations well; however, it does much better with prolonged drought spells.

Figure 4 also shows that the uncertainty of $Q_{95}$ estimates is the largest in the Hoalp. The seasonal runoff variability of Alpine rivers is larger than that of low-land rivers, which makes the model calibration more sensitive to the weights assigned to high and low flows. Hoalp is also more sensitive to the choice of the calibration period, which is a reflection of the high sensitivity of low flows to seasonal climate. In contrast, the uncertainty is smallest in the Gurk and Buwe catchments, where the effect of time variability of the model parameters is of similar magnitude as the effect of the weights in the objective function.

Scenarios of air temperature and precipitation from the four climate model runs are presented in Fig. 5. The largest warming is obtained by HADCM3 with an increase of more than $2{ }^{\circ} \mathrm{C}$ in January and the summer months. In January the ECHAM5-A2 run simulates a decrease in air temperature, whereas the other runs simulate an increase. The ECHAM5 scenarios are consistent for the summer months with an increase in air temperature of about $1^{\circ} \mathrm{C}$. The precipitation projections are regionally less consistent and vary mostly around $\pm 15 \%$. Exceptions are the HADCM3 run which simulates a decrease of almost $30 \%$ in the Gurk and Buwe catchments in August, and the ECHAM5-A1B run which simulates an 
Table 2. Trend extrapolations of average $Q_{95}$ low flows $\left(\mathrm{m}^{3} \mathrm{~s}^{-1}\right)$ for the periods $2021-2050$ and 2051-2080 based on observed trends. Changes (\%) refer to the $Q_{95}$ in the future period relative to the average $Q_{95}$ in the reference period (1976-2008). Values in parentheses indicate $95 \%$ confidence intervals.

\begin{tabular}{rlrrrr}
\hline \multicolumn{1}{c}{ Hoalp } & Muhlv & Gurk & Buwe \\
\hline $2021-2050$ & $Q_{95}\left(\mathrm{~m}^{3} \mathrm{~s}^{-1}\right)$ & $0.28(0.19,0.37)$ & $0.68(0.45,1.02)$ & $1.19(0.58,2.00)$ & $0.02(-0.14,0.14)$ \\
$2021-2050$ & Change $(\%)$ & $+39(-7,+71)$ & $-8(-41,+34)$ & $-36(-72,-1)$ & $-90(-177,-22)$ \\
$2051-2080$ & $Q_{95}\left(\mathrm{~m}^{3} \mathrm{~s}^{-1}\right)$ & $0.35(0.22,0.45)$ & $0.60(0.15,1.14)$ & $0.74(-0.23,2.01)$ & $-0.08(-0.33,0.12)$ \\
$2051-2080$ & Change $(\%)$ & $+74(0,123)$ & $-21(-79,+51)$ & $-59(-113,+9)$ & $-148(-282,-36)$ \\
\hline
\end{tabular}

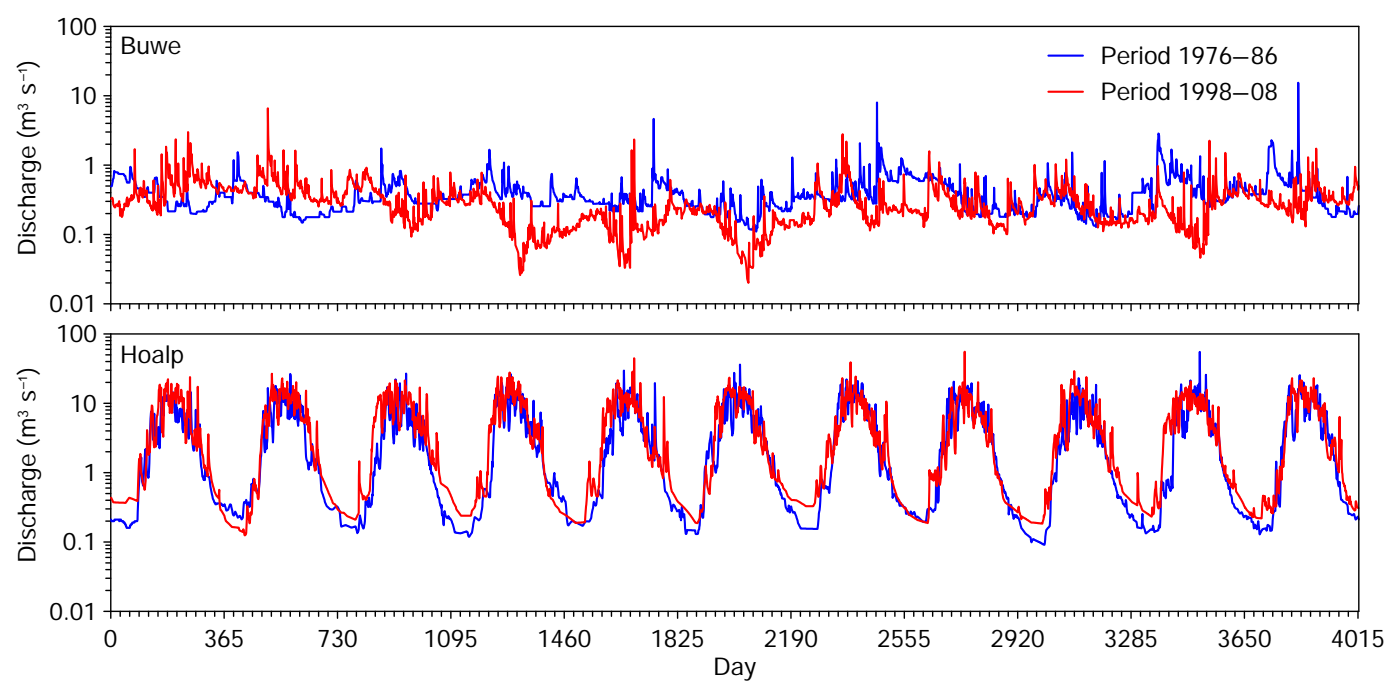

Figure 3. Observed daily discharge for the periods 1976-1986 (blue lines) and 1998-2008 (red lines) in the Buwe (top) and Hoalp (bottom) catchments.

Table 3. Runoff model efficiency $Z_{Q}$ (Eq. 2) obtained for different weights $w_{Q}$ in the four catchments for three calibration periods. $w_{Q}=0$ and $w_{Q}=1$ emphasise low flows and high flow, respectively, in the calibration. $Z_{Q}$ are listed in the sequence of the calibration periods: 1976-1986/1987-1997/1998-2008.

\begin{tabular}{rrrrr}
\hline${ }^{w_{Q}}$ & Hoalp & Muhlv & Gurk & Buwe \\
\hline 0.0 & $0.96 / 0.95 / 0.90$ & $0.82 / 0.84 / 0.86$ & $0.79 / 0.73 / 0.79$ & $0.46 / 0.52 / 0.59$ \\
0.1 & $0.95 / 0.93 / 0.90$ & $0.81 / 0.83 / 0.86$ & $0.79 / 0.73 / 0.79$ & $0.37 / 0.52 / 0.58$ \\
0.2 & $0.94 / 0.92 / 0.90$ & $0.80 / 0.82 / 0.86$ & $0.78 / 0.74 / 0.79$ & $0.35 / 0.53 / 0.58$ \\
0.3 & $0.93 / 0.90 / 0.90$ & $0.79 / 0.81 / 0.86$ & $0.78 / 0.74 / 0.79$ & $0.34 / 0.54 / 0.58$ \\
0.4 & $0.92 / 0.89 / 0.89$ & $0.79 / 0.80 / 0.86$ & $0.78 / 0.74 / 0.79$ & $0.40 / 0.54 / 0.57$ \\
0.5 & $0.91 / 0.88 / 0.89$ & $0.77 / 0.79 / 0.86$ & $0.78 / 0.75 / 0.78$ & $0.36 / 0.55 / 0.56$ \\
0.6 & $0.90 / 0.86 / 0.89$ & $0.77 / 0.78 / 0.86$ & $0.78 / 0.75 / 0.78$ & $0.30 / 0.56 / 0.55$ \\
0.7 & $0.89 / 0.85 / 0.89$ & $0.76 / 0.78 / 0.86$ & $0.78 / 0.75 / 0.78$ & $0.30 / 0.57 / 0.55$ \\
0.8 & $0.88 / 0.83 / 0.75$ & $0.76 / 0.77 / 0.81$ & $0.78 / 0.76 / 0.80$ & $0.30 / 0.58 / 0.49$ \\
0.9 & $0.88 / 0.82 / 0.73$ & $0.75 / 0.76 / 0.81$ & $0.78 / 0.76 / 0.80$ & $0.28 / 0.59 / 0.49$ \\
1.0 & $0.87 / 0.82 / 0.72$ & $0.75 / 0.75 / 0.81$ & $0.78 / 0.77 / 0.81$ & $0.29 / 0.60 / 0.49$ \\
\hline
\end{tabular}

increase of about $30 \%$ in the Hoalp and Muhlv catchments in December.

The delta-change projections for the period 2021-2050 relative to simulated runoff in the reference period are shown in Fig. 6. They indicate an increase of annual $Q_{95}$ low flows in the Alpine Hoalp catchment, which is in the range of 15 to
30 and 20 to $45 \%$ for the different climate projections and calibration weights, respectively. In the Muhlv catchment, changes are small, while for Gurk and Buwe decreases are projected which are around 7-13 and 15-20\%, respectively. $Q_{95}$ is sensitive not only to the selection of the climate scenarios, but also to the selection of the objective function and the calibration period. The uncertainty is the largest in the Hoalp catchment, where the objective function is more important than choice of the climate scenarios. The mean winter air temperature in Hoalp is about $-6.0^{\circ} \mathrm{C}$, which is projected to increase by 2 to $2.5^{\circ} \mathrm{C}$, depending on the scenario. These differences are of little relevance for snow storage and snowmelt runoff during the winter low-flow period. Muhlv and Buwe are also sensitive to the choice of objective function and calibration period, while for the Gurk the choice of climate scenario is more important.

\subsection{Extrapolation of stochastic rainfall characteristics and runoff modelling}

Figure 7 shows that the estimated trend components fit well to the precipitation statistics. Annual mean storm duration decreases quite strongly for the Hoalp (by about 

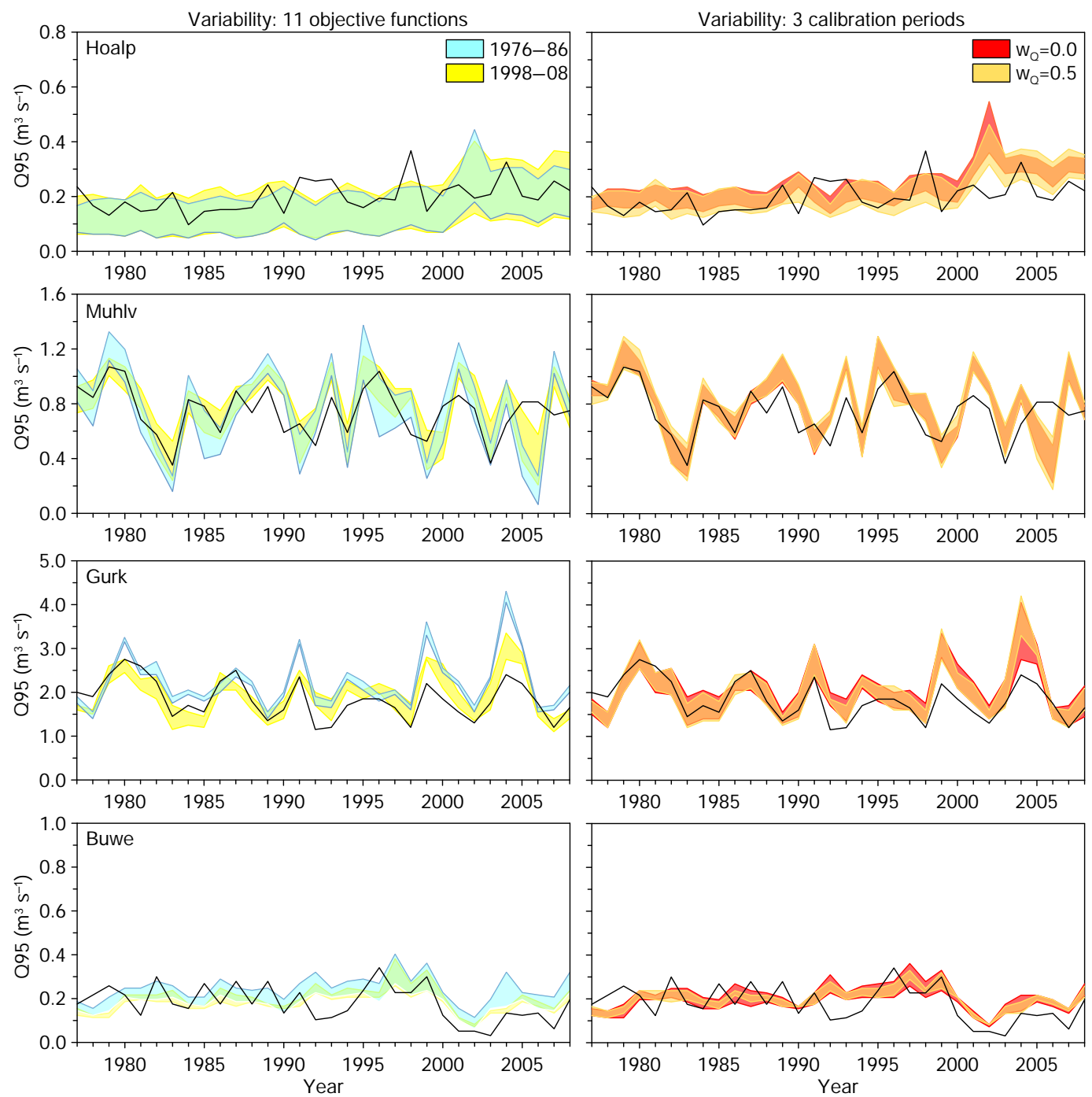

Figure 4. Annual $Q_{95}$ low flows from observed data (black lines) and from hydrologic model simulations (coloured bands) for the four catchments. Band widths in the left panels show the variability due to different weights $w_{Q}$ in the objective function (Table 3) for two calibration periods (1976-1986 and 1998-2008). Band widths in the right panels show the variability due to different decades used for model calibration for two sets of weights $\left(w_{Q}=0.5\right.$ and $\left.w_{Q}=0.0\right)$.

-0.8 days $/ 100$ years). There is also a slight decrease for Gurk ( -0.4 days $/ 100$ years) and Buwe ( -0.3 days $/ 100$ years). Interstorm period and storm intensity (Fig. 7, centre and right panels) show no significant changes, apart from the Gurk where the annual mean interstorm period increases by about 1 day/100 years, and annual mean storm intensity increases by $2 \mathrm{~mm} \mathrm{day}^{-1}$ per 100 years (which is a $30 \%$ increase per 100 years).

The stochastic simulations (Fig. 8) indicate no trends in mean annual precipitation for Muhlv in the north and Gurk in the southern part of Austria, a drying trend for Buwe in the south-east and Hoalp in the Alps, but in the latter case the observations exhibit a rather complex signal that is not well represented by the linear model. The simu- lated temperatures (Fig. 8, right panels) are more consistent with the observations with a persistently increasing trend in all catchments. The trend is most pronounced in the Alps $\left(+4.4^{\circ} \mathrm{C} / 100\right.$ years), somewhat less pronounced in the south and south-east $\left(+2.8\right.$ and $+2.6^{\circ} \mathrm{C} / 100$ years $)$ and there is only a weak trend in the northern $\left(+1.7^{\circ} \mathrm{C} / 100\right.$ years $)$ part of Austria.

Figure 9 shows the stochastic projections of annual runoff and $Q_{95}$ low flows (red lines) together with the observations (black lines). For Hoalp (top row) $Q_{95}$ decreases only slightly despite the simulated large decrease of annual runoff and precipitation. This is because winter low flows are more controlled by air temperatures that increase the low flows, and the two effects essentially cancel. For Muhlv (second 

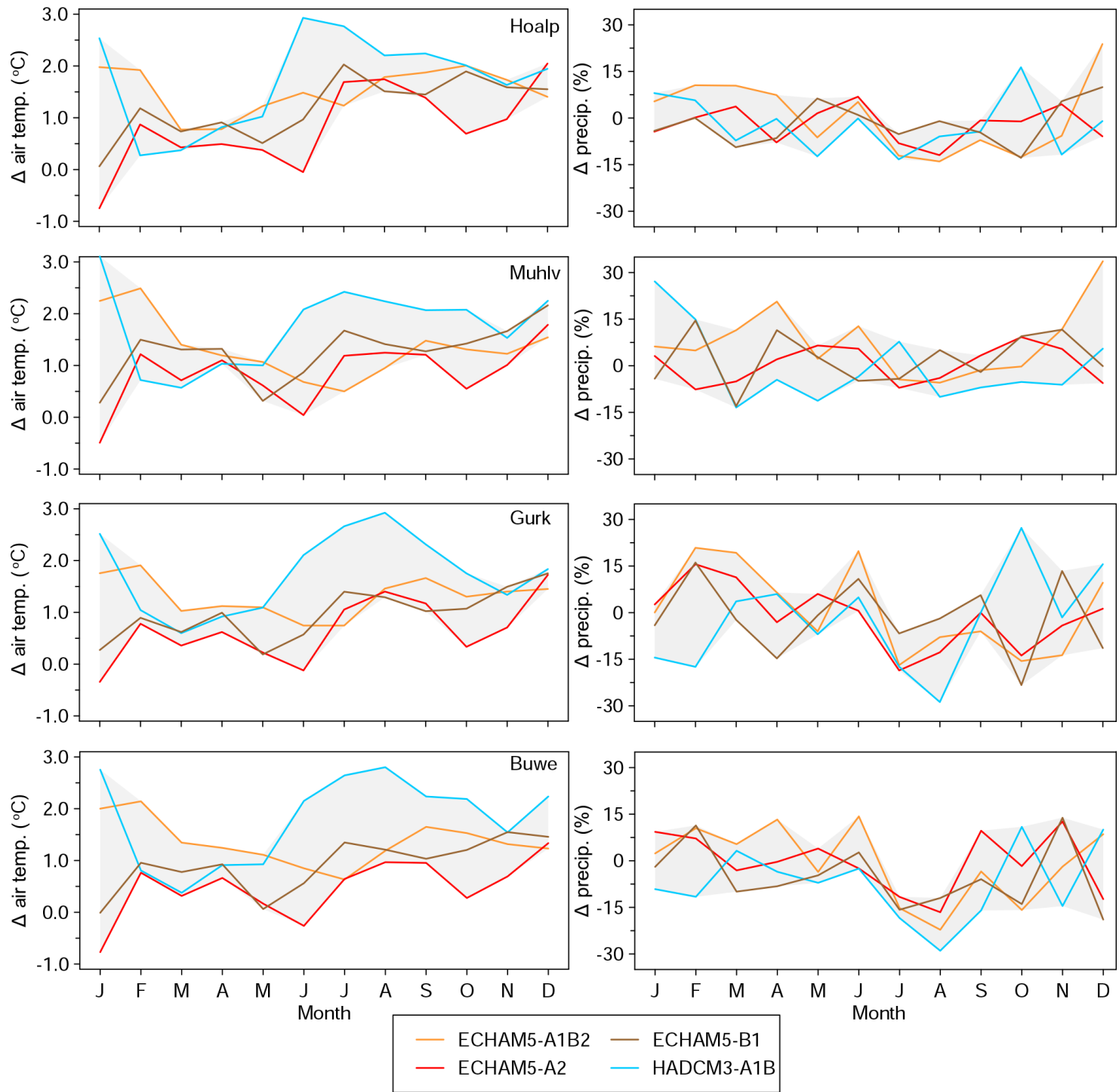

Figure 5. Projections of air temperatures and precipitation for the four catchments simulated by regional climate models. Shown are longterm monthly changes of the future period (2021-2050) relative to the reference period (1976-2008). Shaded areas indicate the range of climate scenarios/models.

row in Fig. 9), the model extrapolates a slight reduction of $Q_{95}$ in the future, even though there is hardly any change in the annual precipitation (second row in Fig. 8), which is due to increases in the evaporation. For Gurk (third row in Fig. 9), the model also extrapolates a slight decrease in $Q_{95}$, which is a result of the increasing trends in both evaporation and the interstorm period (Figs. 7 and 8). For Buwe (bottom row in Fig. 9), the extrapolations yield a moderately decreasing trend of $Q_{95}$, which results from the combined effect of slightly decreasing precipitation and increasing evaporation.

The underlying assumption about observed trends in precipitation and temperature to persist into the future is quite strong. In contrast to the other pillars, here we do not consider the uncertainty associated with the estimation (and ex- trapolation) of the trends. The confidence bounds in Figs. 9 and 10 represent the modelled variability of the low-flow producing processes, which are assumed to be known both in the present and in the future. Despite the strong assumptions made it should be noted that the results of this approach are non-trivial, as the way the trends in precipitation and temperature translate into trends in low flows differs between the catchments because of non-linear process interactions. 

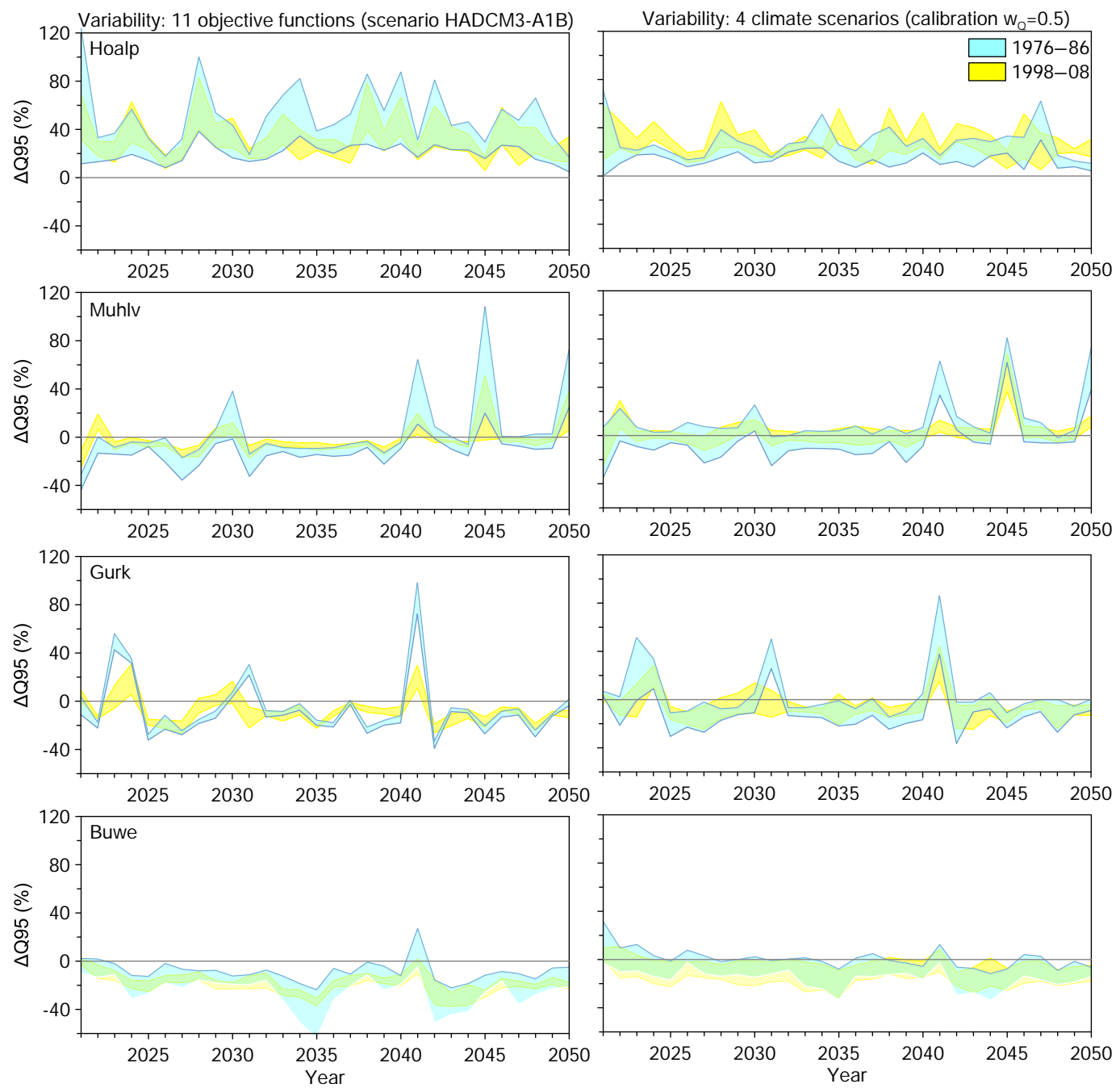

Figure 6. Projections of annual $Q_{95}$ low flows for the four catchments in terms of changes of the future period (2021-2050) relative to simulated runoff in the reference period (1976-2008). Band widths in the left panels show the variability due to different weights $w_{Q}$ in the objective function (Table 3) using HADCM3. Band widths in the right panels show the variability due to the choice of climate projections for calibration variant $w_{Q}=0.5$. Yellow and blue colours relate to two calibration periods for the hydrological model.

\section{Three-pillar synthesis}

\subsection{Combination of information}

The concept of multi-model ensembles starts with the premise that (a) a group of model projections will give more reliable results than the individual models alone and (b) the consistency/inconsistency of the model results is an indicator of the robustness or reliability of the projections (Knutti et al., 2010). In the context of the three-pillar approach proposed here, the methods and information used in each pillar are largely independent of each other, so one would expect the errors to be close to independent, and a combination of the projections should indeed increase the overall reliability of the projection. We will evaluate heuristically to what degree this premise can be achieved based on hydrological reasoning and visual comparisons of synoptic plots of the individual estimates and their respective confidence bounds. The reasoning accounts for the differences in the nature of the uncertainties of the projections and gives more weight to the more reliable pieces of information.

When comparing the projections two cases exist. In the first case, projections are consistent within their confidence bounds. This will lend credence to all projections as they support each other, in particular if the changes of the driving hydrological processes (precipitation, snow storage and melt, evaporation) are consistent. The overall uncertainty will be expressed here as three levels of confidence (high, medium, low; Field and Intergovernmental Panel on Climate Change, 2012). In the second case, the individual projections are not consistent within their uncertainty bounds, which will sug- 

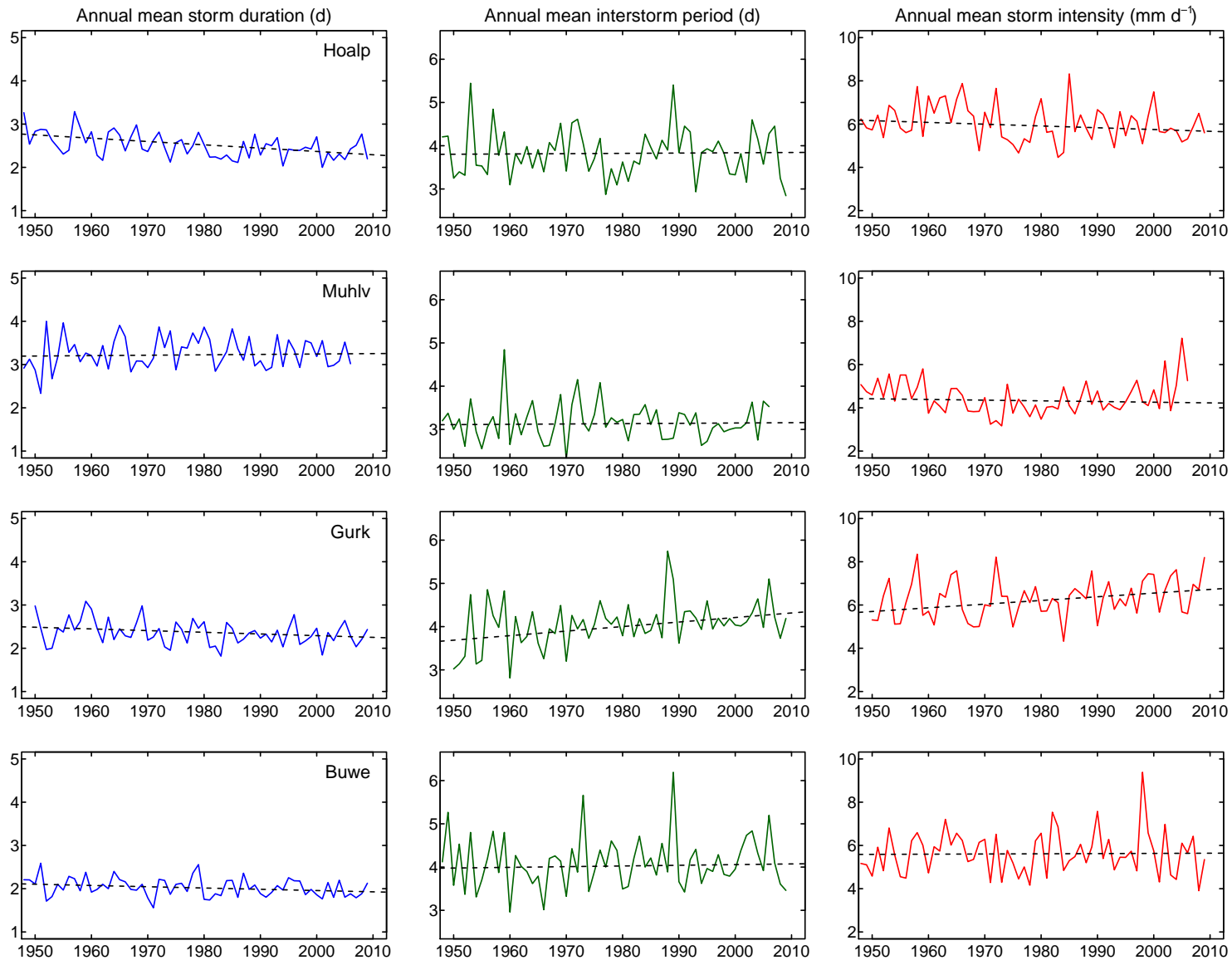

Figure 7. Observed trends in the precipitation statistics for the climate stations St. Jakob Def (Hoalp), Pabneukirchen (Muhlv), Klagenfurt (Gurk) and Wöerterberg (Buwe). The trend lines (dashed) have been fitted with the Theil-Sen method.

gest lower confidence in the overall projections. Rather than simply averaging the individual projections, here, we explore the reasons for the disagreement, by checking the credibility of each projection based on the data used and the assumptions made.

\subsection{Application to the study area}

Figure 10 compiles the $Q_{95}$ projections from the three pillars, and Fig. 11 shows their probability density functions for the period 2021-2050.

For the Hoalp region in the Alps (Fig. 10, top left), both the extrapolation of observed low-flow trends and the climate scenarios suggest increases in low flows. In this region, low flows occur in winter due to snow storage processes that are mainly driven by seasonal temperature (Fig. 3). Schöner et al. (2012) showed that regional climate models have been able to simulate the observed increase of winter temperatures in the Alpine region since the 1970s well, which suggests that the winter low-flow changes are captured well by the climate scenarios. However, a lot of uncertainty is introduced by the parameterisations of the rainfall-runoff model as indicated by the wide boxes in Fig. 10. This uncertainty is due to the sensitivity of the simulations to the model parameters in an Alpine environment (Figs. 4 and 6). From a regional perspective (Fig. 2), the observed low-flow trends are significant; i.e. the percentage of stations with a significant trend is much greater than expected by chance (Blöschl et al., 2011). This means that the climate scenarios and the trend extrapolations can be reconciled, at least in terms of the sign of the changes. The stochastic extrapolations, in contrast, project no or even slightly decreasing low-flow trends. A closer inspection of observed air temperatures suggests that winter temperatures $\left(+0.65^{\circ} \mathrm{C} / 10\right.$ years) have changed more by half than the annual average $\left(+0.46^{\circ} \mathrm{C} / 10\right.$ years in the period 1976-2010). However, the stochastic model assumes a constant change throughout the year, which results in underestimates of future $Q_{95}$. Of course, the model could be straightforwardly extended to include seasonal variations in the changes but, as it is now, it nicely illustrates the case of an inconsistency that is well understood. Because of this, little weight is given to the stochastic projections in the overall assessment, and one would expect an increase in low flows by at least $20-40 \%$ for the 2021-2050 period with medium to high confidence. 

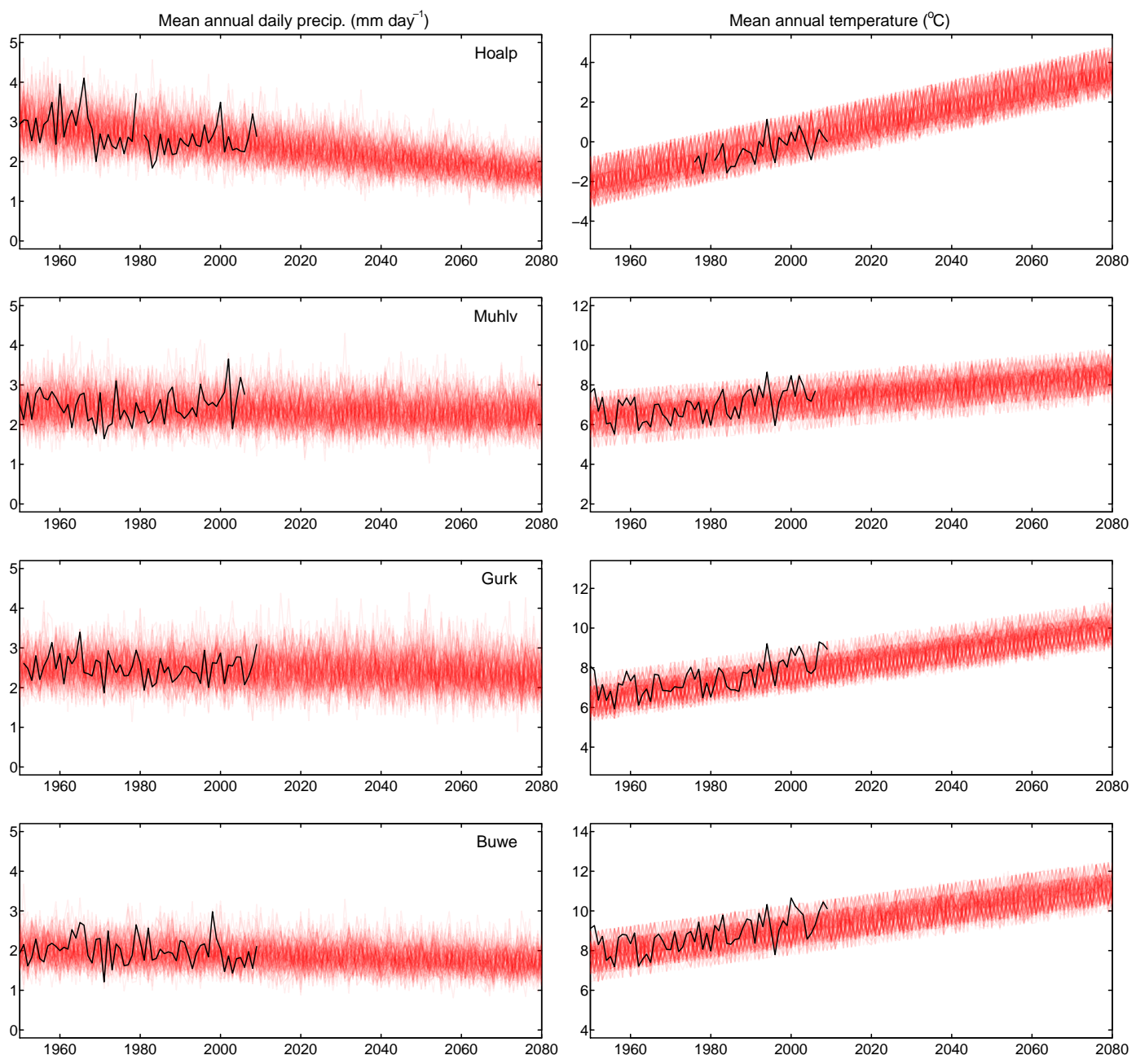

Figure 8. Stochastic simulations of mean annual precipitation and mean annual temperature (red lines) for St. Jakob Def (Hoalp), Pabneukirchen (Muhlv), Klagenfurt (Gurk) and Wöerterberg (Buwe); 100 simulated time series for each station. For comparison, observations are shown (black lines).

For the Muhlv region north of the Alps, the extrapolation of observed low-flow trends corresponds well with the stochastic projections (Fig. 10 top right). Both methods project a slight reduction of about $5-10 \%$ for $2021-$ 2050. Seasonal air temperature trends are similar to the annual trends $\left(0.43^{\circ} \mathrm{C} / 10\right.$ years in the period $\left.1976-2010\right)$, so the structure of the stochastic model is appropriate here. The rainfall-runoff simulations capture the observed trend well for the observation period. The climate scenarios predict a slight decrease in $Q_{95}$ for 2021-2050 but there is a lot of variability between the scenarios (also see Fig. 5). On a regional level, Blöschl et al. (2011) reported no field significance of the observed low-flow trends in this region which, together with the three pillars, here suggests a slight tendency for decreasing low flows in 2021-2050 with medium confidence. For the 2051-2080 period all methods become more uncertain, but all point towards a drying trend (low to medium confidence).
The Gurk region south of the Alps (Fig. 10 bottom left) shows a somewhat similar behaviour to Muhlv, although the observed low-flow pattern is rather non-linear with a drop at the beginning of the observations and a flattening out after 1990. Extrapolating a linear trend in low flows may therefore not be reliable. The stochastic projections are more in line with the observations and indicate a slight decrease until 2080. Winter SPEI in the period 1961-2003 is not simulated well (Fig. 1), which suggests issues with the seasonal water balance of the GCM-based simulations. However, the climate scenario projections are in line with extrapolated trends and stochastic projections. All pillars point to a slight to moderate drying trend in low flows for the 2021-2050 period (medium confidence) and towards a somewhat stronger drying trend for 2051-2080 (low to medium confidence).

The Buwe region in the south-east gives larger changes (Fig. 10, bottom right). The observed low-flow trends are strongly influenced by the recent dry years between 2000 

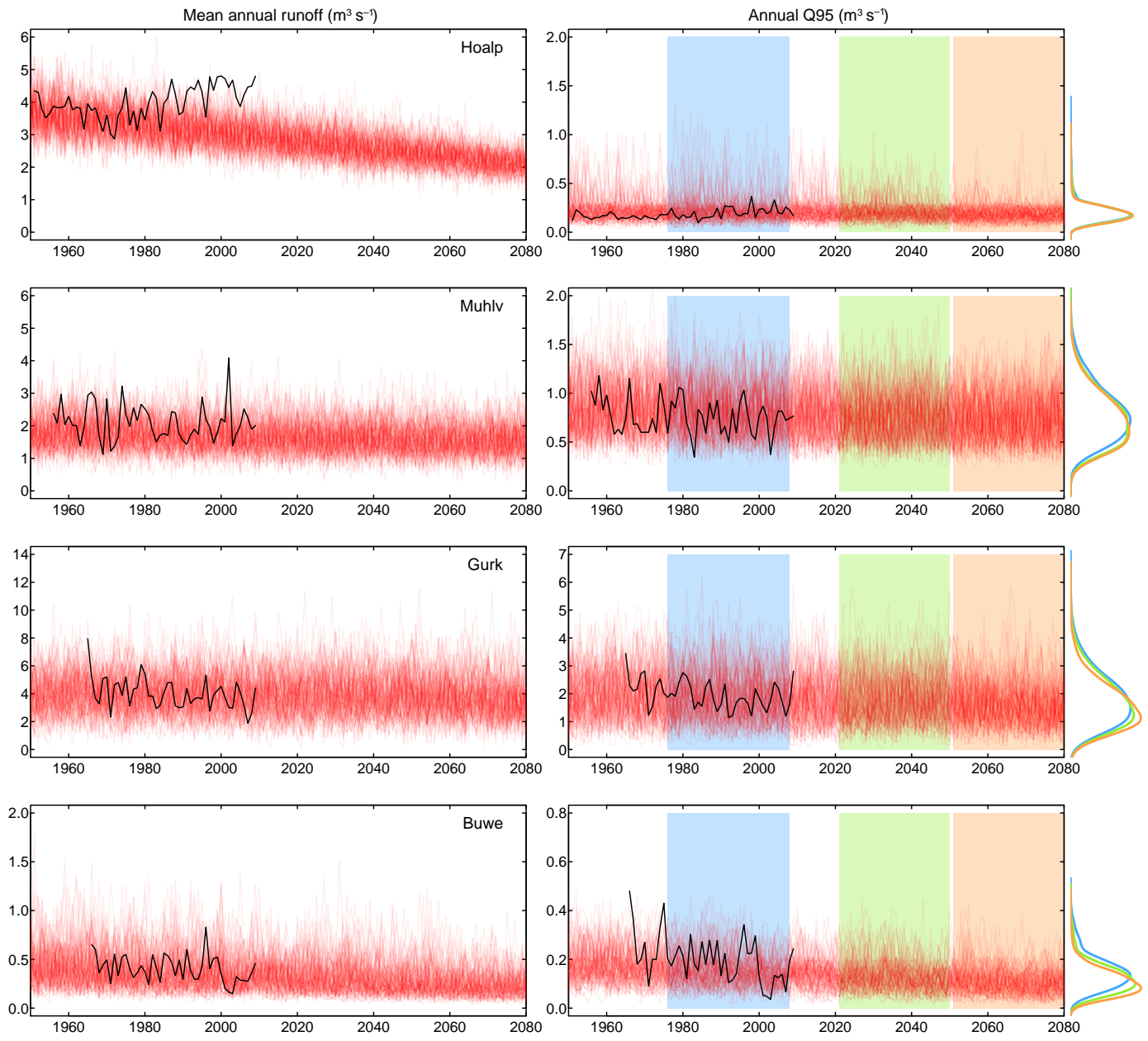

Figure 9. Stochastic simulations of mean annual runoff and annual $Q_{95}$ (red lines) assuming linear extrapolation of the rainfall model parameters for the Hoalp, Muhlv, Gurk and Buwe catchments; 100 simulated time series for each catchment. For comparison, observations are shown (black lines). Probability density functions of $Q_{95}$ for three periods are shown on the right.

and 2005, which is consistent with the regional behaviour (Fig. 2 and Blöschl et al., 2011). A linear trend extrapolation, however, does not seem very plausible, in particular because the most recent year in the data set (2008) was less dry. In fact, more recent data for 2009-2014 (not included in the analysis) show that low flows have partly recovered (annual Q95 values ranging from 0.1 to $0.3 \mathrm{~m}^{3} \mathrm{~s}^{-1}$ ) illustrating the limitations of trend extrapolation. The stochastic projection yields a moderately decreasing trend, which is more plausible, and related to both increasing temperatures and decreasing precipitation (Fig. 8). The climate scenarios give slightly stronger decreasing trends for the two periods, but it should be noted that, in contrast to the other catchments, the summer SPEI trend in the period 1961-2003 is not captured well and likely overestimated by the climate simulations (Fig. 1, top right). Figure 2 shows consistently decreasing trends of observed streamflow in the region. Overall, the pillars therefore point towards a slight to moderate drying trend for 2021-2050, and a stronger drying trend for 20512080 with medium confidence.

\section{Discussion}

\subsection{Extrapolation of observed low-flow trends}

The trend scenarios are based on the assumption that changes are linear over time. This is a simplifying view of nonstationarity. The Earth system is clearly non-linear, so often regime shifts are observed rather than trends. These can be detected in a similar way as trends (see, e.g., Rodionov, 2006) but it is more difficult to make assumptions about persistence of change than for the case of linear trends. In the European Alps, annual air temperatures have increased linearly since the mid-1970s, so a continuing trend is a plausible assumption about the near future. Trends in air temperatures translate into changes in low flows in a non-linear way and 

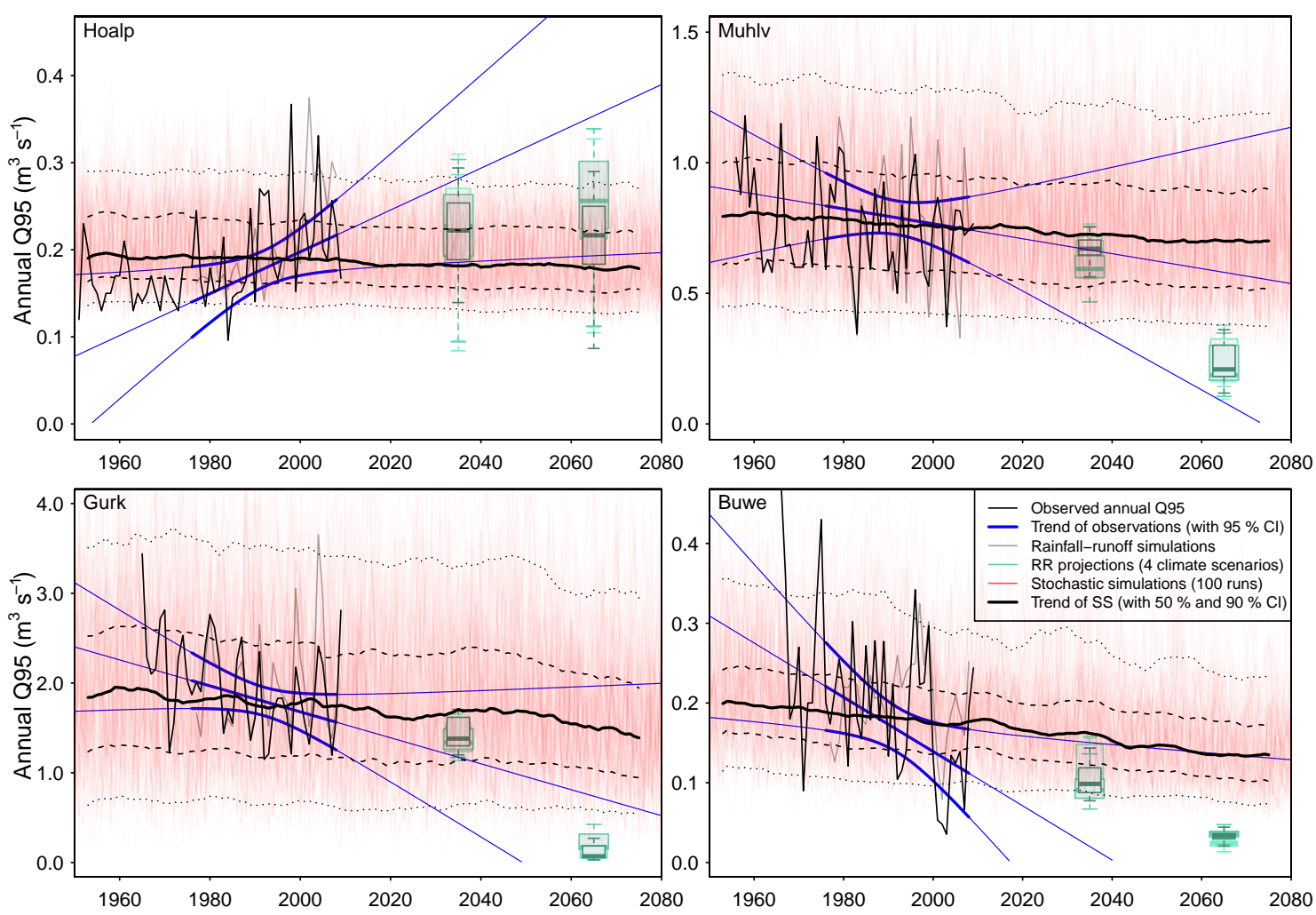

Figure 10. Three-pillar projections of annual $Q_{95}$ low flows for the Hoalp, Muhlv, Gurk and Buwe catchments. Black lines refer to observed annual $Q_{95}$. Pillar 1: extrapolation of observed low-flow trends (blue) and 0.95 level confidence bounds (blue curved lines); bold/thin parts refer to observation/extrapolation period. Pillar 2: simulations in the observation period (grey line), and climate projections and runoff modelling for 2021-2050 and 2051-2080 (box plots, shades of green indicate different climate scenarios, range of box plots indicates different parameters of the hydrological model). Pillar 3: extrapolation of stochastic rainfall characteristics and runoff modelling (100 realisations, red lines) with 0.50 level (black dashed lines) and 0.90 level (black dotted lines) confidence bounds.

this depends on the time of the year low flows occur (Laaha and Blöschl, 2006). Winter low flows are a consequence of frost and snow storage, which is reflected by a remarkable co-behaviour of observed low flows with temperature for the Alpine Hoalp catchment (Fig. 10 top left).

For the other catchments that exhibit a summer low-flow regime, the past changes of low flows are more subtle. The flow records are rather short, so discerning trends from long range fluctuations is difficult (Montanari et al., 1997). In all cases, the uncertainty of the trend scenarios is large, as indicated by the wide confidence bounds. It should be noted that the confidence bounds are conditional on the assumption that the linear trend model applies. If one relaxed this assumption, the bounds would be even wider. Part of the uncertainty comes from the relatively short record length (33 years). Hannaford et al. (2013) showed that low-flow trends in European regimes are subject to pronounced decadal-scale variability so that even post- 1960 trends (50 years) are often not consistent with the long-term pattern. Long climate records may assist in trend detection. Haslinger et al. (2014) found that the SPEI is a good proxy of summer low flows in the study area where the HISTALP data set (Auer et al., 2007) al- lows for analysing climate fluctuations back to the year 1800 (Fig. 1). The decreasing trends of summer SPEI from the climate projections (Fig. 1) are in line with the low-flow trends in Muhlv and Gurk, and both point to a decrease of low flows that extends into the future.

\subsection{Climate projections and runoff modelling}

Similar to the ensemble projections of Wong et al. (2011), Majone et al. (2012) and De Wit et al. (2007), we assessed the uncertainty arising from the choice of the climate model and emission scenario. We did not assess downscaling errors, as De Wit et al. (2007) did, as they usually play a minor role when using a delta-change approach that applies a change factor to locally observed signals. Uncertainty arising from the hydrological model structure may also be assessed by a model ensemble (e.g. Habets et al., 2013) but we have chosen to focus on the uncertainty of model parameters instead. The results suggest that the $Q_{95}$ projections are not only sensitive to the choice of climate scenarios, but also to the objective function and the calibration period. The uncertainty associated with the objective function is largest in the 

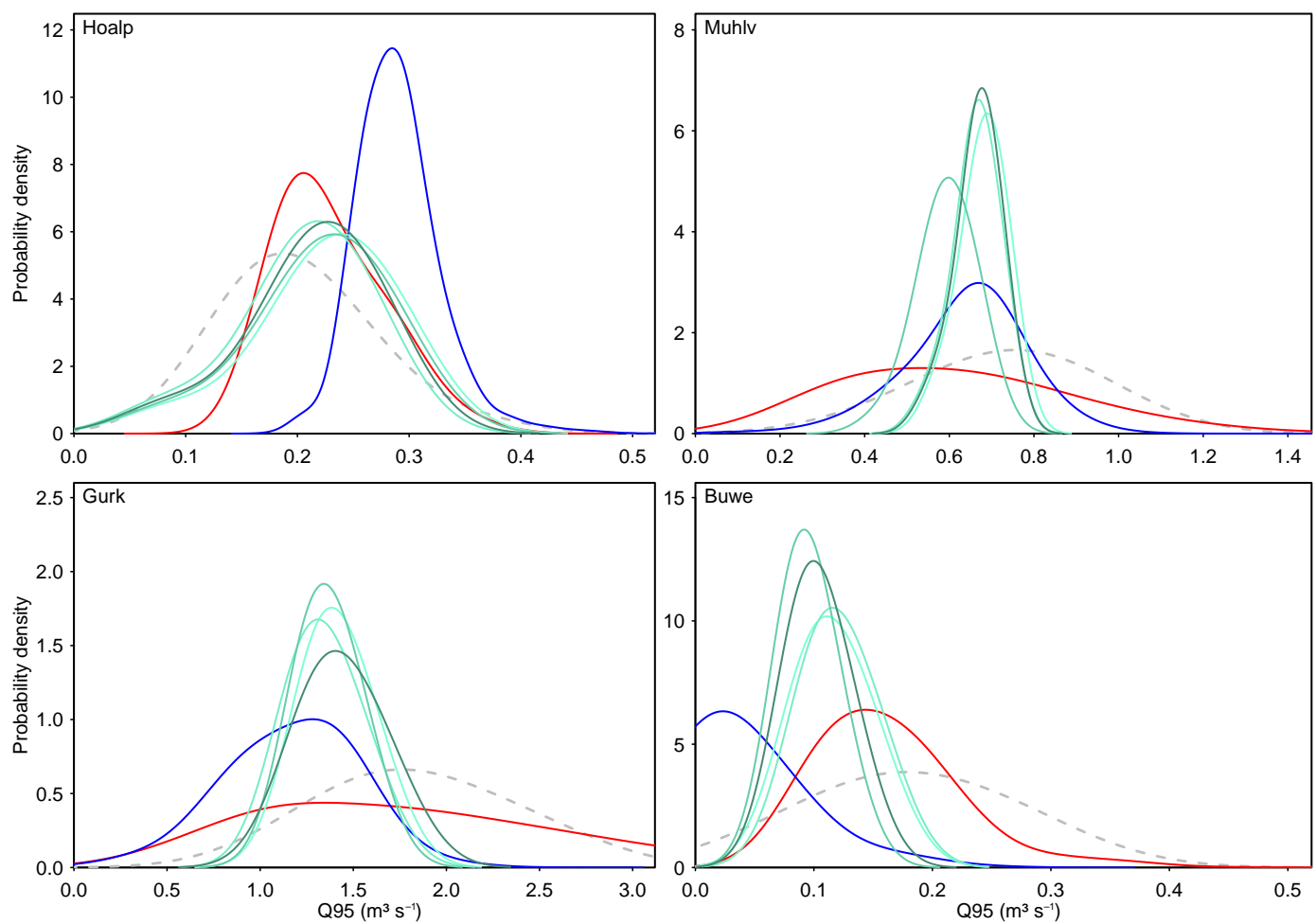

Figure 11. Probability density functions (pdf's) of annual $Q_{95}$ low flows 2021-2050 of the three-pillar projections for the Hoalp, Muhlv, Gurk and Buwe catchments as in Fig. 10. Pillar 1: extrapolation of observed low flows (blue). Pillar 2: climate projections and runoff modelling (different shades of green). Pillar 3: extrapolation of stochastic rainfall characteristics and runoff modelling (red). The pdf's represent both variability within the period and uncertainty (pillars 1 and 2) and variability alone (pillar 3). For comparison, observed $Q_{95}$ in the reference period (1976-2008) is shown (dashed grey line).

Alpine Hoalp catchment, where the strong streamflow seasonality makes the weighting between high and low flows particularly important. The uncertainty associated with the calibration period is largest in Buwe and Gurk where parameters from a colder period with less evaporation tend to overestimate runoff in warmer periods. A similar effect is expected for a future, warmer climate, so the projected low flows may decrease more strongly than the projected average. This finding may depend both on model type and the climate region. Hay et al. (2000), for example, found a minor role of the hydrological model for three river basins in the USA, although they did not specifically examine the time stability of model parameters. Bosshard et al. (2013), on the other hand, suggested that the hydrological model accounted for $5-40 \%$ of the total streamflow ensemble uncertainty in the Alpine Rhine. Similarly, Samaniego et al. (2013) found that accounting for hydrological model parameter uncertainty is essential for identifying drought events, and multi-parameter ensembles were efficiently able to identify the magnitude of that uncertainty.

Low-flow projections are challenging because low flows are typically driven by groundwater discharge processes (both recharge and discharge). These processes are difficult to understand and model due to their local nature. Flecken- stein et al. (2006), for example, found that the percentage of river channel responsible for $50 \%$ of total river seepage during low-flow conditions in the Cosumnes River, California, ranged from 10 to $26 \%$ depending on the spatial configuration of hydrogeologic heterogeneity. This heterogeneity has not been resolved in the present study and is rarely resolved in catchment-scale climate assessment studies. It is therefore important to note that, while the climate drought processes tend to be rather large scale, the catchment response during low-flow periods can have specific local effects, which differ from those of the larger-scale pattern.

\subsection{Extrapolation of stochastic rainfall characteristics and runoff modelling}

Stochastic models of rainfall characteristics can be conditioned to future climates in a number of ways (see, e.g., Hall et al., 2014). A common method is to first calibrate the model parameters to the current climate and then adjust the parameters to precipitation from climate scenarios at daily, seasonal and annual timescales (e.g. Hundecha and Merz, 2012; Blöschl et al., 2011). To illustrate the three-pillar approach we have adopted here the very simple assumption about extrapolating the trends in the rainfall model parameters and 
air temperatures linearly into the future. The reasoning, and the limitations, are similar to the direct trend extrapolation of low flows, building on the inertia of the climate system. Consequently, the extrapolation of temperature will be more appropriate than that of precipitation and the extrapolation into the near future will be more appropriate than that into the more distant future.

Alternative stochastic models could be used within the same three-pillar framework. The model could be adjusted to climate scenarios in a similar way as the model of Hundecha and Merz (2012), and correlations between precipitation and air temperature could be accounted for. Also, the long range dependence of streamflow (Szolgayová et al., 2014) could be considered by extending the stochastic precipitation model (e.g. Thyer and Kuczera, 2003). This will result in more complex patterns of future simulated low flows.

\subsection{Assessing the value of synthesis}

Climate impact and assessment studies in hydrology have traditionally been dominated by the paradigm of modelling cascades (Blöschl and Montanari, 2010), so a fresh look at the problem for the particular case of low flows opens up a number of opportunities. The three-pillar approach allows for a diverse set of methods based on different assumptions and data to be compared and combined in a coherent way. For the case study catchment Muhlv in the region north of the Alps, for example, consistently small low-flow changes are projected by all methods, which adds credence to the projections. The synthesis framework proposed here puts a lot of emphasis on heuristic process reasoning. This may contribute to a better understanding of low-flow response to a future climate than a mere examination of scenario results. For an Alpine region such as Austria, the key to understanding low flows is whether they are controlled by freezing and snowmelt processes, or by the summer moisture deficit associated with evaporation. Understanding of the key processes helps putting the projections from the diverse methods into perspective. For example, for the Alpine Hoalp catchment this reasoning points towards increasing low flows, which is also consistent with all three pillars adopted here. In a similar way, Luce and Holden (2009) and Luce et al. (2013) explained decreasing low-flow trends in the Pacific Northwest of the USA by declines in mountain precipitation and suggested that this trend will persist into the future. Luce et al. (2013) pointed out that in their study initial interpretations of apparently consistent trends would have been misleading, partly due to artefacts in data, missing information and overextrapolation of trends, which triggered additional analyses leading to a differing perception of hydrological change. This example illustrates the importance of careful process reasoning in every step of the analysis.

The three-pillar approach also provides opportunities for a more complete assessment of the uncertainty of the projections. The multi-model ensemble premise of variations between ensemble members being an indicator of projection uncertainty is consistent with the case study findings of this paper. For example, the comparisons of the methods for the Hoalp catchment highlighted issues with the assumption about a uniform seasonal temperature change of the stochastic model, so less credibility was given to this pillar in this particular case. For the Buwe catchment, non-linear changes of observed low flows shed doubts on the linear-trend assumption, so less credibility was given to the low-flow extrapolation pillar. On the other hand, for predicting nearfuture low flows in the Hoalp catchment, the trend extrapolation appears most reliable. From trend extrapolations alone one would infer a $39 \%$ increase in low flows until 20212050 (Table 2) but the uncertainty is of equal magnitude. Additional information from rainfall-runoff projections that suggest an increase of up to $30 \%$ constrain the projected increase to about 20 to $40 \%$.

In the context of water resources management, decision makers are usually reluctant to use the output from black box models as the sole basis of their decisions. Just as important as the expected changes in the water system are the uncertainties associated with the changes as well as a process reasoning in terms of cause and effect. This is particular the case if robust drought management strategies, such as the vulnerability approach, are to be adopted (Wilby and Dessai, 2010; Blöschl et al., 2013). Typically, these strategies are designed to perform well over a wide range of assumptions about the future and potentially extremely negative effects. Central to the approach is an understanding of the cause-effect relationships within the water system under a variety of conditions, as well as an appreciation of the possible uncertainties. Methods often involve exploratory modelling approaches (Watts et al., 2012), which fit well with the three-pillar approach proposed here. We therefore believe that the approach put forward in this paper can play an important role in assisting risk managers in developing drought management strategies for the practice.

It should be emphasised that the extrapolation pillars have been adopted here to illustrate the framework and could be replaced by other methods such as the "trading space for time" approach (Perdigão and Blöschl, 2014) where spatial gradients are transposed into temporal changes. Also, heuristic process reasoning has been adopted to compare the pillars based on expert judgement because of its flexibility. The combination could be based on formal methods (e.g. Bayesian methods, Viglione et al., 2013) that allow accounting for subjective information on low flows and their process causes. Finally, the three-pillar approach presented in this paper is not necessarily restricted to low flows and could be adapted to other hydrologic characteristics. 


\section{Conclusions}

We propose a framework that combines low-flow projections from different sources of information, termed pillars. To illustrate the framework three pillars have been chosen: (a) direct extrapolation of low-flow trends, (b) estimation of low flows from GCM-projected climates using a runoff model and (c) stochastic simulations from trend-extrapolated climates using a similar runoff model.

The methods and information used in each pillar are largely independent from each other, so one would expect the errors to be close to independent, and a combination of the projections should increase the overall reliability of the projection. We evaluate heuristically to what degree this premise can be achieved for four example regions in Austria, based on hydrological reasoning and visual comparisons of synoptic plots of the individual estimates and their respective confidence bounds.

For the Alpine region where winter low flows dominate, trend projections and climate scenarios yield consistent projections of a wetting trend but of different magnitudes. For the region north of the Alps, all methods project rather small changes. For the regions in the south and south-east more pronounced and mostly decreasing trends are projected but there is disagreement in the magnitude of the changes. The synthesis of the case study projections suggests that the framework (i) tends to enhance the robustness of the overall assessment, (ii) adds to the understanding of the cause-effect relationships of low flows and (iii) sheds light on the uncertainties involved based on the consistency/inconsistency of the pillars.

Future work may be directed towards adding pillars, or replacing some of the pillars used here. One possibility is historic information from archives and tree-ring analyses that would allow for assessment of a wider spectrum of drought conditions. Other possibilities are the "trading space for time" approach as well as more formal multi-model ensembles.

Acknowledgements. The paper is a contribution to UNESCO's FRIEND-Water program. The authors would like to thank the Austrian Climate Research Program ACRP for financial support through the projects CILFAD (GZ B060362) and DALF-Pro (GZ B464822), and the Austrian Academy of Sciences for financial support through the "Predictability of Runoff" project. We thank the Central Institute for Meteorology and Geodynamics (ZAMG) and the Hydrographical Service of Austria (HZB) for providing meteorological and hydrological data, and Tobias Gauster for assistance with Fig. 10. We would like to thank Luis Samaniego, Charlie Luce and Chuck Kroll for their useful comments on the manuscript.

Edited by: K. Stahl

Reviewed by: L. Samaniego, C. Kroll, and C. Luce

\section{References}

Auer, I., Böhm, R., Jurkovic, A., Lipa, W., Orlik, A., Potzmann, R., Schöner, W., Ungersböck, M., Matulla, C., Briffa, K., Jones, P., Efthymiadis, D., Brunetti, M., Nanni, T., Maugeri, M., Mercalli, L., Mestre, O., Moisselin, J.-M., Begert, M., MüllerWestermeier, G., Kveton, V., Bochnicek, O., Stastny, P., Lapin, M., Szalai, S., Szentimrey, T., Cegnar, T., Dolinar, M., GajicCapka, M., Zaninovic, K., Majstorovic, Z., and Nieplova, E.: HISTALP - historical instrumental climatological surface time series of the Greater Alpine Region, Int. J. Climatol., 27, 17-46, doi:10.1002/joc.1377, 2007.

Blöschl, G. and Montanari, A.: Climate change impacts-throwing the dice?, Hydrol. Process., 24, 374-381, 2010.

Blöschl, G., Viglione, A., Merz, R., Parajka, J., Salinas, J. L., and Schöner, W.: Auswirkungen des Klimawandels auf Hochwasser und Niederwasser (Climate impacts on floods and low flows), Österr. Wasser- Abfallwirtsch., 63, 21-30, 2011.

Blöschl, G., Viglione, A., and Montanari, A.: Emerging Approaches to Hydrological Risk Management in a Changing World, in Climate Vulnerability, 3-10, Elsevier, 2013.

Böhm, R., Auer, I., Brunetti, M., Maugeri, M., Nanni, T., and Schöner, W.: Regional temperature variability in the European Alps: 1760-1998 from homogenized instrumental time series, Int. J. Climatol., 21, 1779-1801, doi:10.1002/joc.689, 2001.

Bosshard, T., Carambia, M., Goergen, K., Kotlarski, S., Krahe, P., Zappa, M., and Schär, C.: Quantifying uncertainty sources in an ensemble of hydrological climate-impact projections, Water Resour. Res., 49, 1523-1536, doi:10.1029/2011WR011533, 2013.

Ceola, S., Arheimer, B., Baratti, E., Blöschl, G., Capell, R., Castellarin, A., Freer, J., Han, D., Hrachowitz, M., Hundecha, Y., Hutton, C., Lindström, G., Montanari, A., Nijzink, R., Parajka, J., Toth, E., Viglione, A., and Wagener, T.: Virtual laboratories: new opportunities for collaborative water science, Hydrol. Earth Syst. Sci., 19, 2101-2117, doi:10.5194/hess-19-2101-2015, 2015.

Chauveau, M., Chazot, S., Perrin, C., Bourgin, P.-Y., Sauquet, E., Vidal, J.-P., Rouchy, N., Martin, E., David, J., Norotte, T., Maugis, P., and De Lacaze, X.: Quels impacts des changements climatiques sur les eaux de surface en France à l'horizon 2070?, Houille Blanche, 4, 5-15, doi:10.1051/lhb/2013027, 2013.

De Wit, M. J. M., Van den Hurk, B., Warmerdam, P. M. M., Torfs, P. J. J. F., Roulin, E., and Van Deursen, W. P. A.: Impact of climate change on low-flows in the river Meuse, Climate Change, 82, 351-372, doi:10.1007/s10584-006-9195-2, 2007.

Diaz-Nieto, J. and Wilby, R. L.: A comparison of statistical downscaling and climate change factor methods: impacts on low flows in the River Thames, United Kingdom, Climate Change, 69, 245-268, 2005.

Douglas, E., Vogel, R., and Kroll, C.: Trends in floods and low flows in the United States: impact of spatial correlation, J. Hydrol., 240, 90-105, 2000.

Duan, Q., Sorooshian, S., and Gupta, V.: Effective and efficient global optimization for conceptual rainfall-runoff models, Water Resour. Res., 28, 1015-1031, 1992.

Efron, B. and Tibshirani, R. J.: An introduction to the bootstrap Chapman \& Hall, New York, 436 pp., 1993.

Field, C. B. and Intergovernmental Panel on Climate Change: Managing the risks of extreme events and disasters to advance climate change adaption: special report of the Intergovernmental Panel 
on Climate Change, Cambridge University Press, New York, 2012.

Fleckenstein, J. H., Niswonger, R. G., and Fogg, G. E.: Riveraquifer interactions, geologic heterogeneity, and low-flow management, Ground water, 44, 837-852, 2006.

Gaál, L., Szolgay, J., Kohnová, S., Parajka, J., Merz, R., Viglione, A., and Blöschl, G.: Flood timescales: Understanding the interplay of climate and catchment processes through comparative hydrology, Water Resour. Res., 48, W04511, doi:10.1029/2011WR011509, 2012.

Giuntoli, I., Renard, B., Vidal, J.-P., and Bard, A.: Low flows in France and their relationship to large-scale climate indices, J. Hydrol., 482, 105-118, doi:10.1016/j.jhydrol.2012.12.038, 2013.

Gupta, H.V., Blöschl, G., McDonnel, J., Savenije, H., Sivapalan, M., Viglione, A., and Wagener, T.: Synthesis, in: Runoff Prediction in Ungauged Basins - Synthesis across Processes, Places and Scales, edited by: Blöschl, G., Sivapalan, M., Wagener, T., Viglione, A., and Savenije, H., Chapter 12, 361-383, Cambridge University Press, Cambridge, UK, 2013.

Gutknecht, D., Blöschl, G., Reszler, C., and Heindl, H.: Ein "Mehr-Standbeine"-Ansatz zur Ermittlung von Bemessungshochwässern kleiner Auftretenswahrscheinlichkeit, Österr. Wasser- Abfallwirtsch., 58, 44-50, 2006.

Habets, F., Boé, J., Déqué, M., Ducharne, A., Gascoin, S., Hachour, A., Martin, E., Pagé, C., Sauquet, E., Terray, L., Thiéry, D., Oudin, L. and Viennot, P.: Impact of climate change on the hydrogeology of two basins in northern France, Climate Change, 121, 771-785, doi:10.1007/s10584-013-0934-x, 2013.

Hall, J., Arheimer, B., Borga, M., Brázdil, R., Claps, P., Kiss, A., Kjeldsen, T. R., Kriauciuniene, J., Kundzewicz, Z. W., Lang, M., Llasat, M. C., Macdonald, N., McIntyre, N., Mediero, L., Merz, B., Merz, R., Molnar, P., Montanari, A., Neuhold, C., Parajka, J., PerdigÃo, R. A. P., Plavcová, L., Rogger, M., Salinas, J. L., Sauquet, E., Schär, C., Szolgay, J., Viglione, A., and Blöschl, G.: Understanding flood regime changes in Europe: a state-of-the-art assessment, Hydrol. Earth Syst. Sci., 18, 27352772, doi:10.5194/hess-18-2735-2014, 2014.

Hannaford, J. and Buys, G.: Trends in seasonal river flow regimes in the UK, J. Hydrol., 475, 158-174, 2012.

Hannaford, J., Buys, G., Stahl, K., and Tallaksen, L. M.: The influence of decadal-scale variability on trends in long European streamflow records, Hydrol. Earth Syst. Sci., 17, 2717-2733, doi:10.5194/hess-17-2717-2013, 2013.

Haslinger, K., Anders, I., and Hofstätter, M.: Regional climate modelling over complex terrain: an evaluation study of COSMOCLM hindcast model runs for the Greater Alpine Region, Clim. Dynam., 40, 511-529, 2013.

Haslinger, K., Koffler, D., Schöner, W., and Laaha, G.: Exploring the link between meteorological drought and streamflow: Effects of climate-catchment interaction, Water Resour. Res., 50, 2468 2487, doi:10.1002/2013WR015051, 2014.

Hay, L. E., Wilby, R. L., Leavesley, G. H.: A comparison of delta change and downscaled GCM scenarios for three mountainous basins in the United States, J. Am. Water Resour. Assoc., 36, 387-397, doi:10.1111/j.1752-1688.2000.tb04276.x, 2000.

Hundecha, Y. and Merz, B.: Exploring the relationship between changes in climate and floods using a model-based analysis, Water Resour. Res., 48, doi:10.1029/2011WR010527, 2012.
Hurkmans, R., Terink, W., Uijlenhoet, R., Torfs, P., Jacob, D., and Troch, P. A.: Changes in streamflow dynamics in the Rhine basin under three high-resolution regional climate scenarios, J. Climate, 23, 679-699, 2010.

Knutti, R., Abramowitz, G., Collins, M., Eyring, V., Gleckler, P. J., Hewitson, B., and Mearns, L.: Good Practice Guidance Paper on Assessing and Combining Multi Model Climate Projections, in: Meeting Report of the Intergovernmental Panel on Climate Change Expert Meeting on Assessing and Combining Multi Model Climate Projections, edited by: Stocker, T. F., Qin, D., Plattner, G.-K., Tignor, M., and Midgley, P. M., IPCC Working Group I Technical Support Unit, University of Bern, Bern, Switzerland, 2010.

Laaha, G. and Blöschl, G.: Seasonality indices for regionalizing low flows, Hydrol. Process., 20, 3851-3878, doi:10.1002/hyp.6161, 2006.

Laaha, G. and Blöschl, G.: A national low flow estimation procedure for Austria, Hydrol. Sci. J., 52, 625-644, doi:10.1623/hysj.52.4.625, 2007.

Lins, H. F. and Slack, J. R.: Streamflow trends in the United States, Geophys. Res. Lett., 26, 227-230, 1999.

Loibl, W., Formayer, H., Schöner, W., Truhetz, H., Anders, I., Gobiet, A., Heinrich, G., Köstl, M., Nadeem, I., Peters-Anders, J., Schicker, I., Suklitsch, M., and Züger, H.: Reclip: century 1 Research for climate protection: century climate simulations: models, data and ghg-scenarios, simulations, ACRP Final Rep. Reclip Century Part Vienna, 2011.

Lorenzo-Lacruz, J., Vicente-Serrano, S. M., López-Moreno, J. I., Morán-Tejeda, E., and Zabalza, J.: Recent trends in Iberian streamflows (1945-2005), J. Hydrol., 414-415, 463-475, doi:10.1016/j.jhydrol.2011.11.023, 2012.

Luce, C. H. and Holden, Z. A.: Declining annual streamflow distributions in the Pacific Northwest United States, 1948-2006, Geophys. Res. Lett., 36, L16401, doi:10.1029/2009GL039407, 2009.

Luce, C. H., Abatzoglou, J. T., and Holden, Z. A.: The Missing Mountain Water: Slower Westerlies Decrease Orographic Enhancement in the Pacific Northwest USA, Science, 342, 1360 1364, doi:10.1126/science.1242335, 2013.

Majone, B., Bovolo, C. I., Bellin, A., Blenkinsop, S., and Fowler, H. J.: Modeling the impacts of future climate change on water resources for the Gállego river basin (Spain), Water Resour. Res., 48, W01512, doi:10.1029/2011WR010985, 2012.

Merz, R. and Blöschl, G.: Flood frequency hydrology: 2. Combining data evidence, Water Resour. Res., 44, W08433, doi:10.1029/2007WR006745, 2008.

Merz, R., Parajka, J., and Blöschl, G.: Time stability of catchment model parameters: Implications for climate impact analyses, Water Resour. Res., 47, W02531, doi:10.1029/2010WR009505, 2011.

Montanari, A., Rosso, R., and Taqqu, M. S.: Fractionally differenced ARIMA models applied to hydrologic time series: Identification, estimation, and simulation, Water Resour. Res., 33, 1035 1044, 1997.

Parajka, J. and Blöschl, G.: The value of MODIS snow cover data in validating and calibrating conceptual hydrologic models, J. Hydrol., 358, 240-258, doi:10.1016/j.jhydrol.2008.06.006, 2008.

Parajka, J., Merz, R., and Blöschl, G.: Uncertainty and multiple objective calibration in regional water balance modelling: case 
study in 320 Austrian catchments, Hydrol. Process., 21, 435446, doi:10.1002/hyp.6253, 2007.

Parajka, J., Blaschke, A. P., Blöschl, G., Haslinger, K., Hepp, G., Laaha, G., Schöner, W., Trautvetter, H., Viglione, A., and Zessner, M.: Uncertainty contributions to low-flow projections in Austria, Hydrol. Earth Syst. Sci., 20, 2085-2101, doi:10.5194/hess-20-2085-2016, 2016.

Perdigão, R. A. P. and Blöschl, G.: Spatiotemporal flood sensitivity to annual precipitation: Evidence for landscapeclimate coevolution, Water Resour. Res., 50, 5492-5509, doi:10.1002/2014WR015365, 2014.

Prudhomme, C., Young, A., Watts, G., Haxton, T., Crooks, S., Williamson, J., Davies, H., Dadson, S., and Allen, S.: The drying up of Britain? A national estimate of changes in seasonal river flows from 11 Regional Climate Model simulations, Hydrol. Process., 26, 1115-1118, doi:10.1002/hyp.8434, 2012.

Renard, B., Lang, M., Bois, P., Dupeyrat, A., Mestre, O., Niel, H., Sauquet, E., Prudhomme, C., Parey, S., Paquet, E., Neppel, L., and Gailhard, J.: Regional methods for trend detection: Assessing field significance and regional consistency, Water Resour. Res., 44, W08419, doi:10.1029/2007WR006268, 2008.

Rodionov, S. N.: Use of prewhitening in climate regime shift detection, Geophys. Res. Lett., 33, L12707, doi:10.1029/2006GL025904, 2006.

Samaniego, L., Kumar, R., and Zink, M.: Implications of Parameter Uncertainty on Soil Moisture Drought Analysis in Germany, J. Hydrometeorol., 14, 47-68, doi:10.1175/JHM-D-12075.1, 2013.

Schöner, W., Böhm, R., and Auer, I.: 125 years of high-mountain research at Sonnblick Observatory (Austrian Alps) - from "the house above the clouds" to a unique research platform, Theor. Appl. Climatol., 110, 491-498, 2012.

Sen, P. K.: Estimates of the regression coefficient based on Kendall's tau, J. Am. Stat. Assoc., 63, 1379-1389, 1968.

Sivapalan, M., Blöschl, G., Zhang, L., and Vertessy, R.: Downward approach to hydrological prediction, Hydrol. Process., 17, 21012111, doi:10.1002/hyp.1425, 2003.

Sivapalan, M., Blöschl, G., Merz, R., and Gutknecht, D.: Linking flood frequency to long-term water balance: Incorporating effects of seasonality, Water Resour. Res., 41, W06012, doi:10.1029/2004WR003439, 2005.

Stahl, K., Hisdal, H., Hannaford, J., Tallaksen, L. M., van Lanen, H. A. J., Sauquet, E., Demuth, S., Fendekova, M., and Jódar, J.: Streamflow trends in Europe: evidence from a dataset of nearnatural catchments, Hydrol. Earth Syst. Sci., 14, 2367-2382, doi:10.5194/hess-14-2367-2010, 2010.

Stedinger, J. R. and Tasker, G. D.: Regional hydrologic analysis: 1. Ordinary, weighted, and generalized least squares compared, Water Resour. Res., 21, 1421-1432, 1985.
Szolgayová, E., Laaha, G., Blöschl, G., and Bucher, C.: Factors influencing long range dependence in streamflow of European rivers, Hydrol. Process., 28, 1573-1586, 2014.

Thyer, M. and Kuczera, G.: A hidden Markov model for modelling long-term persistence in multi-site rainfall time series 1., Model calibration using a Bayesian approach, J. Hydrol., 275, 12-26, 2003.

Van Loon, A. F. and Laaha, G.: Hydrological drought severity explained by climate and catchment characteristics, J. Hydrol., 526, 3-14, doi:10.1016/j.jhydrol.2014.10.059, 2015.

Vicente-Serrano, S. M., Beguería, S., and López-Moreno, J. I.: A multiscalar drought index sensitive to global warming: the standardized precipitation evapotranspiration index, J. Climate, 23, 1696-1718, 2010.

Viglione, A. and Parajka, J.: TUWmodel: Lumped Hydrological Model for Education Purposes, R package, available at: http://CRAN.R-project.org/package=TUWmodel (last access: 28 September 2015), 2014.

Viglione, A., Castellarin, A., Rogger, M., Merz, R., and Blöschl, G.: Extreme rainstorms: Comparing regional envelope curves to stochastically generated events, Water Resour. Res., 48, W01509, doi:10.1029/2011WR010515, 2012.

Viglione, A., Merz, R., Salinas, J. L., and Blöschl, G.: Flood frequency hydrology: 3. A Bayesian analysis, Water Resour. Res., 49, 675-692, doi:10.1029/2011WR010782, 2013.

Watts, G., von Christierson, B., Hannaford, J., and Lonsdale, K. Testing the resilience of water supply systems to long droughts, J. Hydrol., 414, 255-267, 2012.

Wilby, R. L. and Dessai, S.: Robust adaptation to climate change, Weather, 65, 180-185, 2010.

Wilson, D., Hisdal, H., and Lawrence, D.: Has streamflow changed in the Nordic countries? - Recent trends and comparisons to hydrological projections, J. Hydrol., 394, 334-346, doi:10.1016/j.jhydrol.2010.09.010, 2010.

Wilson, E. O.: Consilience: the unity of knowledge, New York: Knopf, 1998.

Wong, W. K., Beldring, S., Engen-Skaugen, T., Haddeland, I., and Hisdal, H.: Climate Change Effects on Spatiotemporal Patterns of Hydroclimatological Summer Droughts in Norway, J. Hydrometeorol., 12, 1205-1220, doi:10.1175/2011JHM1357.1, 2011.

Yue, S., Pilon, P., Phinney, B., and Cavadias, G.: The influence of autocorrelation on the ability to detect trend in hydrological series, Hydrol. Process., 16, 1807-1829, 2002. 